This item was submitted to Loughborough's Research Repository by the author.

Items in Figshare are protected by copyright, with all rights reserved, unless otherwise indicated.

\title{
Advancing the multiscale understanding on solid oxide electrolysis cells via modelling approaches: a review
}

\section{PLEASE CITE THE PUBLISHED VERSION}

https://doi.org/10.1016/j.rser.2021.110863

\section{PUBLISHER}

Elsevier BV

VERSION

AM (Accepted Manuscript)

\section{PUBLISHER STATEMENT}

This paper was accepted for publication in the journal Renewable and Sustainable Energy Reviews and the definitive published version is available at https://doi.org/10.1016/j.rser.2021.110863.

\section{LICENCE}

CC BY-NC-ND 4.0

\section{REPOSITORY RECORD}

Li, Zheng, Hao Zhang, Haoran Xu, and Jin Xuan. 2021. "Advancing the Multiscale Understanding on Solid Oxide Electrolysis Cells via Modelling Approaches: A Review”. Loughborough University. 
1 Advancing the multiscale understanding on solid oxide electrolysis cells via

2 modelling approaches: A review

3

4 Zheng $\mathrm{Li}^{1}$, Hao Zhang ${ }^{2, *}$, Haoran $\mathrm{Xu}^{1}$, Jin Xuan ${ }^{1, *}$

5

61 Department of Chemical Engineering, Loughborough University, Loughborough,

7 LE11 3TU, UK

82 School of Engineering, The University of Edinburgh, Edinburgh, EH9 3FB, UK

9 * Corresponding authors: Hao.Zhang-1@ed.ac.uk (H. Zhang), j.xuan@lboro.ac.uk (J. 10 Xuan)

11

12 Abstract

13 Solid oxide electrolysis cell (SOEC) is a clean and highly efficient technology that 14 converts electrical energy into chemical energy, which is regarded as a promising 15 approach to enable hydrogen production, carbon dioxide utilization and nitrogen 16 reduction, and more. One of the main challenges faced by SOEC is performance 17 descending. Numerical modelling is expected to provide insights on performance evolution and material degradation. Different assumptions and methodologies are applied to model the physicochemical processes in a length scale from molecule scale to system scale. It is rational and can be brought great convenience into modelling to 21 make assumptions and simplifications when focusing on a single length scale, however, valuable details can be missing. Multiscale modelling is expected to maintain more information and generate a systematic understanding of the working mechanism

24 of SOEC. In this paper, the modelling methods at various scale levels are summarized. 25 Then, the recent advances in numerical studying on SOEC are reviewed with a focus 
1 on multiscale modelling works bridging two or more contiguous length scales. The

2 challenges and future research directions are proposed to promote the multiscale 3 modelling.

4

5 Keywords: Solid oxide electrolysis cell, multiscale modelling, performance 6 optimization, sustainable fuel

7 Word Count: 11606

8

9 Nomenclature:

AEC Alkaline electrolyser cell

BoP Balance of plant

CFD Computational fluid dynamics

DEM Discrete element method

DFT Density functional theory

DGM Dusty-Gas model

DME Dimethyl ether

FM Fick's model

KMC Kinetic Monte Carlo

LBM Lattice Boltzmann Method

LSCF Lanthanum Strontium Cobalt Ferrite

MC Monte Carlo

MD Molecular dynamics

MR Methanation reaction

PEMEC Proton exchange membrane electrolyser cell

RWGSR Reverse water gas shift reaction 
SDC Samarium-doped ceria

SMM Stefan-Maxwell model

SOEC Solid oxide electrolysis cell

SOFEC Fuel-assisted SOEC

TPB Triple phase boundary 


\section{1. Introduction}

2 As fossil fuels is still the dominant energy source for more than a century, the

3 environmental problems caused by the accumulated $\mathrm{CO}_{2}$ emission have raised global

4 concerns. Many countries and regions have set strict measures to control the $\mathrm{CO}_{2}$

5 emission and laid ambitious targets of decarbonization. For example, both the UK

6 government and the EU have set goals to achieve net-zero greenhouse gas emissions

7 by 2050 [1,2]. Additionally, China, as one of the world's largest emitter, raised a binding

8 target to realise carbon neutral by 2060 [3].

9 Solid oxide electrolysis cell (SOEC) provides a viable option to support the sustainable 10 development of modern society with clean energy. Provided by renewable energies

11 like solar and wind energy, SOEC is capable of producing $\mathrm{H}_{2}$ and hydrocarbons from $12 \mathrm{H}_{2} \mathrm{O}$ electrolysis and $\mathrm{CO}_{2}$ reduction, and even producing ammonia from $\mathrm{N}_{2}$ reduction. 13 As shown in Figure 1 (a), in ion-conducting SOEC, the reactant $\left(\mathrm{H}_{2} \mathrm{O} / \mathrm{CO}_{2}\right)$ is diffused 14 to the interface area of electrolyte, electrode and gas pores, known as triple phase 15 boundary (TPB), where the electrochemical reaction occurs to produce cathodic 16 product $\left(\mathrm{H}_{2} / \mathrm{CO}\right)$, oxygen ion $\left(\mathrm{O}^{2-}\right)$ and electrons. Besides, in proton-conducting SOEC 17 (as shown in Figure 1 (b)), at the anode side, the feed gas $\left(\mathrm{H}_{2} \mathrm{O} / \mathrm{H}_{2}\right)$ provides the protons $\left(\mathrm{H}^{+}\right)$which are transferred through the electrolyte to generate $\mathrm{H}_{2}$ directly, or react with other reagents like $\mathrm{NO}$ and $\mathrm{N}_{2}$ to generate $\mathrm{N}_{2} / \mathrm{N}_{2} \mathrm{O} / \mathrm{NH}_{3}[4,5]$. 


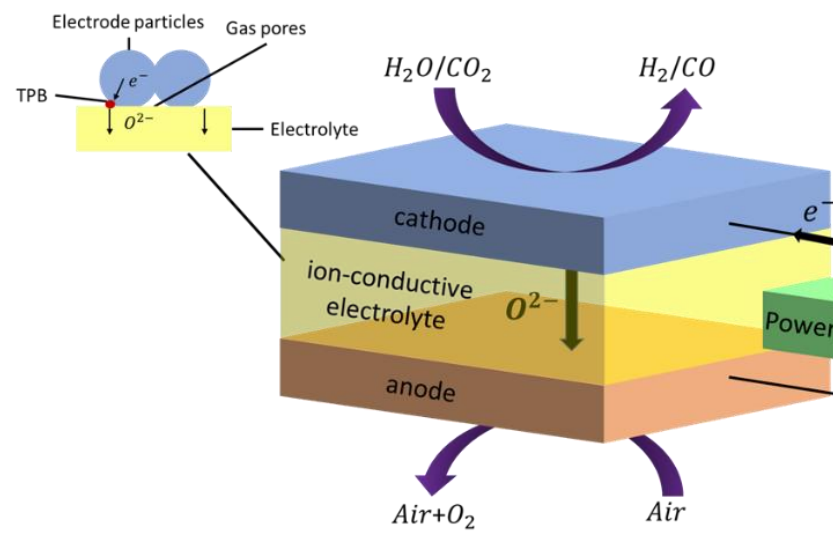

(a)

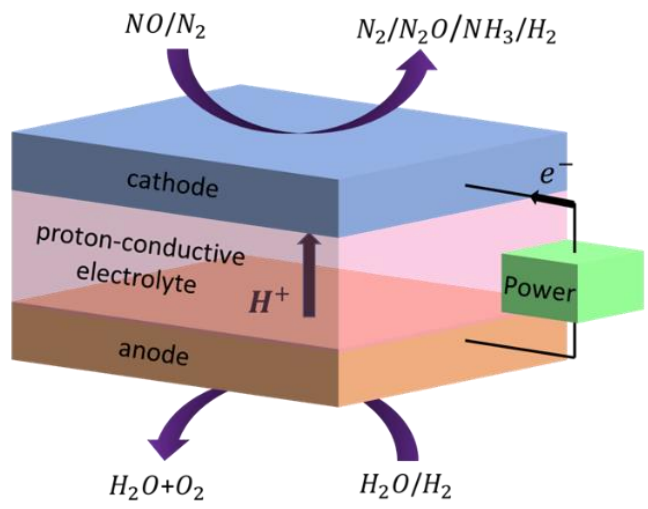

(b)

\begin{tabular}{llll}
\hline Electrolysis technologies & SOEC & PEMEC & AEC \\
\hline Maturity & not yet widely & Commercial & Mature \\
& commercialised & & \\
Voltage efficiency (HHV\%) & $<110[6]$ & $67-82[7]$ & $62-82[7]$ \\
Nominal stack efficiency (LHV\%) & $100[8]$ & $60-68[8]$ & $63-71[8]$ \\
Nominal system efficiency & $76-81[8]$ & $46-60[8]$ & $51-60[8]$ \\
$($ LHV\%) & $<10,000[9]$ & $20,000-90,000$ & $60,000-$ \\
Stack lifetime $(\mathrm{h})$ & $923-1273[11,12]$ & $323-353[7]$ & $90,000[10]$ \\
Operating temperature $(\mathrm{K})$ & $<1[13]$ & $<0.78[7]$ & $<0.17[7]$ \\
Degradation rate $(\% / \mathrm{kh})$ & $>3.2[6]$ & $4.2-5.5[7]$ & $4.2-5.9[7]$ \\
Stack electric energy & & & \\
consumption $\left(\mathrm{kWh} / \mathrm{m}_{\mathrm{H}_{2}}^{3}\right)$ & & & \\
\hline
\end{tabular}

10

11 Due to the high efficiency, SOEC enjoys a much more competitive cost of electricity, 12 especially in high energy price circumstances, according to economic analysis, as 13 shown in Figure 2. 

property of materials. Mesoscale models provide insights into transport processes in microstructures [16]. The macroscale modelling generates strategies for the optimal

Figure 2 Levelized cost of $\mathrm{H}_{2}$ versus electricity price, reproduced with permission [14], copyright 2015, Elsevier.

In recent years, SOEC has undergone rapid development with the state-of-art current density up to $1.9 \times 10^{4} \mathrm{~A} / \mathrm{m}^{2}$. However, SOEC is still facing significant challenges in performance degradation and short lifetime, which is closely related to the material properties [15]. The composition and morphology of materials pose a strong effect on the electrochemical/chemical processes and mass/heat/charge transports within the SOEC as well as the operation lifetime of SOEC. Multiscale numerical modelling provides an opportunity to give a mechanistic description of material performance and thus to guide optimization designs of material and structure. It improves the understanding of the SOEC properties and their effects on the behaviour of the SOEC. For example, electrochemical/chemical reaction kinetics are dominated by the fundamental properties of catalytic sites on the surface of materials. Microscale modelling can be used to study and predict the properties of materials to enhance the reaction kinetics. Mass/charge/heat transfer is governed by the microstructural operations of the SOEC unit and system. In addition, multiscale modelling covers a

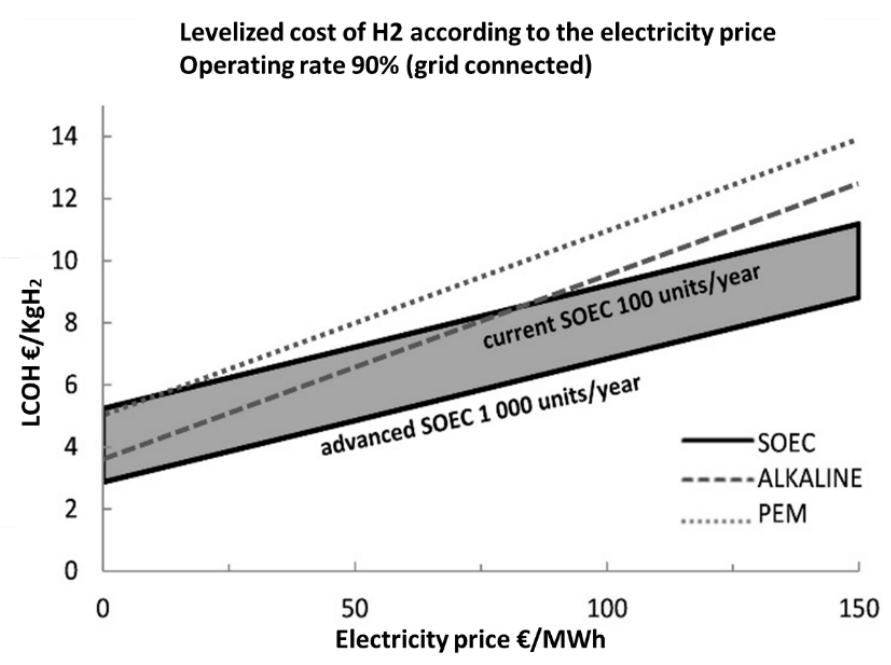


1 large range of time scale (from femtoseconds to hours) and length scale (from

2 Angstroms to meters). Corresponding to different scale models, a variety of numerical

3 modelling approaches have been developed. Specifically, at a certain modelling scale,

4 several mathematical approaches can be adopted to reveal the properties of SOEC

5 on that scale.

6 Many numerical efforts have been devoted to understanding the working mechanism

7 of SOEC from micro to macro scales. It is worth reviewing the researches from the

8 aspect of multiscale modelling to establish a comprehensive understanding of SOEC

9 modelling by introducing various modelling methods suitable for different length scales.

\section{2. Modelling SOEC at different scales}

12 Generally, the modelling of SOEC can be categorized in several ways. In terms of geometry dimension, the models are normally classified into zero-dimension (OD), one-dimension (1D), two-dimension (2D), three-dimension (3D) model. Models can also be categorised as white-box (physical model), black-box (empirical model) and grey-box (semi-empirical model) [17]. The white-box method aims to provide a clear description of physicochemical behaviours in the cell, which is based on objective physical equations and realistic geometric dimensions of cells [18]. Conducting a white-box model requires tremendous work to accomplish the calculations of complex mathematical formulations. In contrast, the black-box method strongly depends on the experimental data [19]. Although the black-box method does not really require a full understanding of the physicochemical processes, large scale of experimental data is required as the input to make sure the model can give reliable predictions [20]. In addition, grey-box, combining the properties of white-box and black-box, requires both physical processes knowledge and experimental data [20,21]. Moreover, SOEC 
1 models can be classified into microscale model, mesoscale model, and macroscale 2 model, in terms of length scale. The macroscale model can be subdivided into cell3 level model, stack-level model, and system-level model. Table 2 summarises the 4 different scales of length and their corresponding modelling methods. 
1 Table 2 Different modelling scales and the corresponding modelling approaches.

\begin{tabular}{|c|c|c|c|c|}
\hline \multicolumn{2}{|c|}{ Modelling scale } & \multicolumn{2}{|c|}{ Modelling methods } & Reference \\
\hline \multirow{3}{*}{$\begin{array}{l}\text { Microsca } \\
\text { le }\end{array}$} & & \multicolumn{2}{|c|}{$\begin{array}{l}\text { Density functional } \\
\text { theory (DFT) }\end{array}$} & {$[28,29,31,42,43]$} \\
\hline & & \multicolumn{2}{|c|}{$\begin{array}{l}\text { Molecular dynamics } \\
\text { (MD) }\end{array}$} & {$[32,37-39]$} \\
\hline & & \multicolumn{2}{|c|}{$\begin{array}{l}\text { Kinetic Monte Carlo } \\
(\mathrm{KMC})\end{array}$} & {$[33,42,43]$} \\
\hline \multirow{5}{*}{$\begin{array}{l}\text { Mesoscal } \\
\text { e }\end{array}$} & & $\begin{array}{l}\text { Lattice } \\
\text { Method (LBN }\end{array}$ & $\begin{array}{l}\text { Boltzmann } \\
\text { ) }\end{array}$ & - \\
\hline & & $\begin{array}{l}\text { Elementary } \\
\text { approach }\end{array}$ & kinetics & {$[45]$} \\
\hline & & \multirow{3}{*}{$\begin{array}{l}\text { Morphology } \\
\text { - } \\
\text { reconstructi } \\
\text { on approach }\end{array}$} & $\begin{array}{l}\text { Stochasti } \\
\text { c } \\
\text { correlatio } \\
\text { n method }\end{array}$ & {$[47,48]$} \\
\hline & & & $\begin{array}{l}\text { Discrete } \\
\text { element } \\
\text { method } \\
\text { (DEM) }\end{array}$ & {$[49,51-54]$} \\
\hline & & & $\begin{array}{l}\text { Monte } \\
\text { Carlo } \\
\text { (MC) }\end{array}$ & {$[49,55]$} \\
\hline
\end{tabular}




\begin{tabular}{|c|c|c|c|}
\hline Cell-level & & $\begin{array}{l}\text { Computational fluid } \\
\text { dynamics (CFD) }\end{array}$ & \multirow[t]{2}{*}{$\begin{array}{l}{[61,62,78-} \\
80,64,69,70,72- \\
76]\end{array}$} \\
\hline & & Continuum approach & \\
\hline $\begin{array}{l}\text { Stack- } \\
\text { level }\end{array}$ & & $\begin{array}{l}\text { Computational fluid } \\
\text { dynamics (CFD) }\end{array}$ & {$[81,84-90,92]$} \\
\hline $\begin{array}{l}\text { System- } \\
\text { level }\end{array}$ & 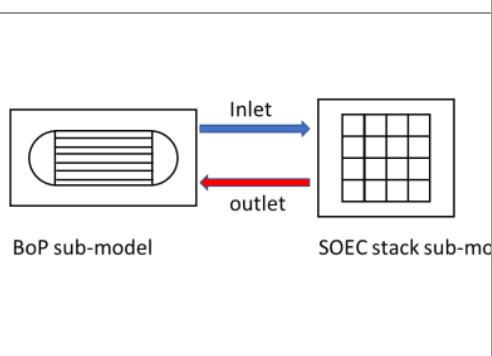 & Process simulation & $\begin{array}{l}{[82,96,109,111,9} \\
7- \\
101,104,105,10 \\
8]\end{array}$ \\
\hline
\end{tabular}

2 The above five scales and the corresponding modelling approaches are reviewed in

3 the following sections. Microscale models are employed to study the detailed

4 electronic structure of materials as well as the atomic/molecular interactions.

5 Mesoscale models provide valuable insights into the transport phenomena and 6 reactions inside the microstructure of SOEC electrodes. In order to conduct multiscale

7 modelling, the reaction kinetics derived from microscale models could be used as the 8 input of mesoscale ones, while the results of mesoscale models provide key

9 parameters for macroscale modelling. The physicochemical information yielded from

10 cell-level modelling can be delivered to build larger stack-level and system-level 11 modelling, which are used to describe the working conditions and macroscopic 12 properties of SOEC stack and whole SOEC system. In the following section, various 13 scales of SOEC models are introduced via the corresponding modelling approaches.

\section{$14 \quad 2.1$ Microscale modelling}

15 The microscale model plays a vital role in understanding the elementary reaction 
1 pathways on the surface of materials from an atomic/molecular view [22]. Microscale

2 modelling is regarded as an effective way to reveal the interaction mechanism

3 between reactants and catalytic surfaces. Thus, it provides practical guides for 4 developing and optimizing catalyst material configuration. There are several 5 accessible approaches for microscale modelling: density functional theory (DFT), 6 kinetic monte carlo (KMC) and molecular dynamics (MD), which are reviewed in detail 7 in the following part.

\section{$8 \quad 2.1 .1$ Density functional theory (DFT)}

9 DFT is a computational quantum chemistry modelling method to investigate electronic10 structure and complex dynamics of multi-particle involved systems [23]. The 11 Schrödinger equation is the fundamental correlation describing the state function of a quantum-mechanical system.

$$
\widehat{H}|\Psi\rangle=E|\Psi\rangle
$$

$$
\widehat{H}=\widehat{T}+\widehat{V}+\widehat{W}
$$

where $E$ is the total energy level of the system; $\Psi$ is the wave function; $\hat{H}$ is Hamiltonian, $\hat{T}$ is the kinetic energy operator; $\hat{V}$ is the potential energy operator, $\hat{W}$ is the electronelectron interaction. DFT is an efficient method to solve the Schrödinger equation. The potential energy surface is a useful conceptual tool for analysing atomic configuration or electrochemical/chemical reaction dynamics and can be derived from the DFT computation [24]. An 'energy landscape' describing the potential energy of a collection of atoms as a function of atomic positions can be provided by potential energy surface [25]. Several commercial software such as VASP and Gaussian are available for DFT calculation [26].

24 In the study of SOEC, one of the most prominent concern is the stability of the 25 materials, which is a challenging problem impeding the SOEC development [27]. From 
1 an atomic level of view, the stability of the structure depends on the level of binding

2 energies. DFT has been using to study the evolution of binding energy and the

3 degradation mechanisms of materials. Rashkeev et al. [28] developed a DFT model

4 to investigate the mechanism of oxygen delamination in the SOEC consisting YSZ and

5 LSM. The formation energies and migration barriers for the defects were calculated.

6 The results indicate that the substitutional defects of Sr and La can strongly affect the

7 migration of oxide ions, and may eventually result in delamination process. In addition,

8 several improvement strategies were proposed to mitigate the oxygen delamination

9 accordingly.

10 Catalysts supported on the electrode strongly affect the electrochemical performance.

11 DFT is used to investigate the role of catalyst atoms on the surface of the support.

12 Cadi-Essadek et al. [29] conducted DFT modelling to assess the stability of various $\mathrm{Ni}$

13 cluster configurations on the $\mathrm{ZrO}_{2}$ and $\mathrm{YSZ}$ using clustering energy as an index. Besides,

14 the cohesive energy and the interaction energy was calculated to understand the

15 interaction among $\mathrm{Ni}$ atoms, and the interaction between the electrolyte surface and the

16 Ni clusters, respectively. It was found that the formation of $\mathrm{Ni}-\mathrm{Ni}$ bond was easier than

17 Ni-electrolyte interaction. As a result, Ni cluster is preferred to form pyramidal shapes

18 rather than flat structures. Under different temperatures, the stability of Ni clusters was

19 affected owing to the aggregation formed by Ni with other atoms or clusters.

20 DFT was also used to evaluate the catalytic/electrocatalytic reactions of gaseous 21 reactants in porous materials [30]. The calculation of interaction site geometries (such

22 as bond lengths and bond angles) can be conducted [30]. Furthermore, in order to 23 understand catalytic reaction kinetics, activation energies through the different 24 reaction pathways can be calculated from DFT. Cadi-Essadek et al. [31] studied the 25 interactions of $\mathrm{CO}_{2}$ with $\mathrm{YSZ}$ and $\mathrm{Nin} / \mathrm{YSZ}(\mathrm{n}=1,4-7,10$ and 20$)$ surfaces. The 
1 calculation results suggested that the surface of $\mathrm{Nin} / \mathrm{YSZ}$ performed better than $\mathrm{YSZ}$ and $\mathrm{Ni}_{1} / \mathrm{YSZ}$ in the aspect of adsorption. The most energetically favourable geometries

3 for $\mathrm{CO}_{2}$ adsorption were proposed (as shown in Figure $3(\mathrm{a})$ ). It is also found that the 4 size of $\mathrm{Ni}$ clusters exerted no effect on the strength of $\mathrm{CO}_{2}$ adsorption.

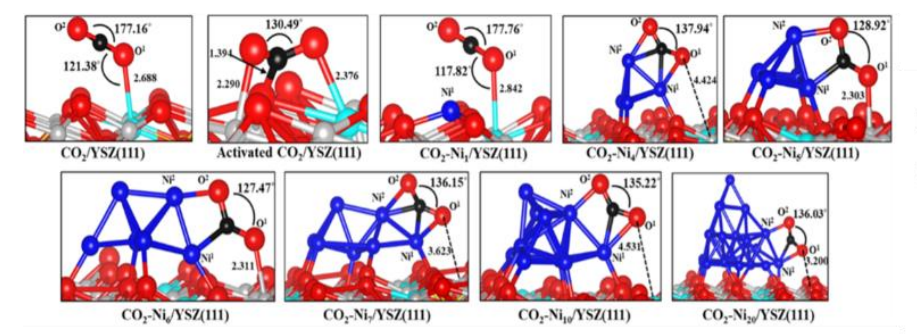

(a)

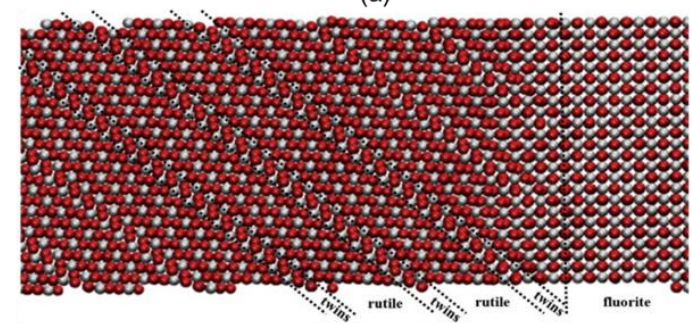

(b)

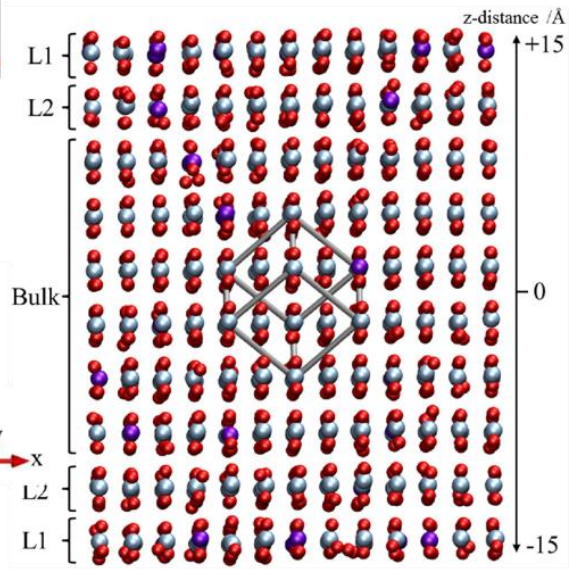

(c)

Figure 3 (a) Most stable configurations of $\mathrm{CO}_{2} / \mathrm{YSZ}$ and $\mathrm{CO}_{2}-\mathrm{Nin}_{n} / \mathrm{YSZ}(n=1,4-7,10$ and 20). Ni, Y, Zr, O, oxygen vacancy and $C$ are represented by blue, cyan, grey, red, yellow and black spheres, respectively, reproduced with permission [31], copyright 2018, American Chemical Society; (b) the coexistence of rutile structure and rutile twin structure, reproduced with permission [32], copyright 2013, Elsevier; (c) a crosssection of double-surfaced $\mathrm{GDC}$ cell after $\mathrm{MC}$ simulation. $\mathrm{Ce}^{4+}, \mathrm{O}^{2-}$ and $\mathrm{Gd}^{3+}$ are represented by blue, red and purple spheres. $L 1$ layer is closest to the surface, then is $L 2$ layers and the bulk. A representative unit cell is shown overlaid on the figure, reproduced with permission [33], copyright 2018, Elsevier.

\subsubsection{Molecular dynamics}

The molecular dynamics (MD) method, can be broadly defined as a physics-based modelling method to investigate a multi-body system, which consists of many 
1 interacting particles [34]. The classical Newton's laws of motion are employed in the

2 MD modelling to describe the motion of molecules. Consequently, MD is commonly

3 used to calculate the particle trajectories and to simulate the interactions between

4 particles. The interactions can be expressed as forms of interatomic potentials, which

5 can be provided by DFT. In order to resolve atomic vibrations accurately, the time step

6 used in the MD method should be short enough to correspond to the time scale of

7 molecular motion [35]. For example, a typical vibration of $\mathrm{C}-\mathrm{H}$ bond corresponds to a

8 period of $10^{-14} \mathrm{~s}$ [35]. Thus, MD is not suitable to simulate a process occurring on a

9 much larger time scale.

10 The MD method has been applied to investigate the transfer processes within the

11 material. It was proved a powerful tool to explore the diffusion coefficient (D) which can be yielded from Einstein formula [36].

$$
<\Delta \mathrm{r}(\mathrm{t})^{2}>=B+6 D t
$$

14 where $\left\langle\Delta r(t)^{2}\right\rangle$ is the mean square displacement of oxygen, $B$ is a constant, $\Delta t$ is the 15 time interval to obtain the mean square displacement of atoms. The diffusivity can convert to conductivity $(\sigma)$ from Nernst-Einstein relation [36]:

$$
\sigma=\frac{\mathrm{DC}\left(\mathrm{q}_{\mathrm{e}}\right)^{2}}{\mathrm{k}_{\mathrm{B}} \mathrm{T}}
$$

where $C$ is the concentration of ionic carriers; $q_{e}$ is the charge, $k_{B}$ is the Boltzmann constant. Li et al. [37] proposed a MD model to investigate the mechanism of ion transfer in YSZ. The results demonstrated that the structural environment of $\mathrm{Zr}^{4+}$ ions was more ordered than that of the $\mathrm{Y}^{3+}$ ions. It was found that the generation of $\mathrm{Y}^{3+-} \mathrm{Y}^{3+}$ clusters can result in a decrease in conductivity when $\mathrm{Y}_{2} \mathrm{O}_{3}$ contents in $\mathrm{YSZ}$ is higher than $8 \%$. Inaba et al. [38] investigated the oxygen diffusion in GDC using MD modelling.

24 The formation enthalpy and lattice parameter of $\mathrm{Gd}-\mathrm{Gd}$ pairs and isolated $\mathrm{Gd}$ ions 
1 were calculated by MD. The results suggested that $\mathrm{Gd}-\mathrm{Gd}$ pairs were more stable

2 than the isolated Gd ions. Additionally, the results also revealed the dependence of

3 the conductivity of GDC on dopant concentration. In terms of short-range interaction,

4 the formation of $\mathrm{Gd}^{3+}$-vacancy-Gd ${ }^{3+}$ clusters impede the oxygen hopping into the

5 vacancy. On the other hand, in terms of long-range interaction, a shorter vacancy-

6 vacancy distance decreases the possibility of oxygen jumping into a vacancy.

7 MD modelling also shows the ability to investigate the mechanical performance of

8 electrolyte and interfaces, i.e., the mechanism of deformation behaviour of the material.

9 Sun et al. [32] measured the deformation behaviour of GDC under uniaxial tensile.

10 The MD modelling results indicated that the GDC structure experienced a phase

11 transformation to a rutile twin structure from a fluorite structure caused by stress when

12 a tensile load was applied in the $\left[\begin{array}{lll}0 & 1 & 0\end{array}\right]$ direction. In contrast, when the load was

13 applied in the direction of [ $\left[\begin{array}{ll}0 & 1\end{array}\right]$, the coexistence of both rutile structure and rutile twin

14 structure was detected (shown in Figure $3(b)$ ).

15 Further, the thermal properties of materials can be explored by the MD method as well.

16 Schelling and Phillpot [39] numerically calculated the thermal conductivity for both

$17 \mathrm{ZrO}_{2}$ and $\mathrm{YSZ}$. The thermal conductivity was found to behave like amorphous 18 materials when the concentration $\mathrm{Y}_{2} \mathrm{O}_{3}$ was greater than $12 \%$. In contrast, when $\mathrm{Y}_{2} \mathrm{O}_{3}$ 19 content is less than $12 \%$, the thermal property of the material behaved like a crystalline 20 solid.

21

\section{2.1.3 Kinetic Monte Carlo (KMC)}

23 Kinetic Monte Carlo (KMC) is a useful tool for simulating the stochastic behaviour of 24 atoms (e.g., diffusion) in the many-particle system and the evolution of the system with 25 time [40]. Different from MD, KMC is a stochastic approach and can generate a series 
1 of microscopic states without considering the equations of particles' motions [41].

2 Therefore, a large time-step can be carried out in KMC modelling.

3 Gunn et al. [33] developed a model (as shown in Figure 3 (c)) to study the diffusion of

4 oxygen and cation in a $10 \mathrm{~mol} \%$ GDC system. In their study, a rigid-ion model with

5 Buckingham potentials was included for simulating the atomic interactions. The

6 composite monte carlo method was applied to yield structures at the condition of

7 thermodynamic equilibrium, while the final output structure from HMC was used as the

8 input structure for adaptive KMC. Then the adaptive KMC was employed to study the

9 diffusion and its mechanism in the GDC. Composite monte carlo results indicated that

$10 \mathrm{Gd}^{3+}$ concentration and oxygen vacancies were augmented at the surface of GDC

11 rather than in the bulk area. As a result, the average activation energy for oxygen

12 migrations from the bulk was twice that from the surface layer. Correspondingly, the

13 ionic conductivity of the bulk area was approximately half of the surface layer.

14 Dopants can have a significant impact on the performance of electrolytes. Through

$15 \mathrm{KMC}$, not only the optimal dopant concentration but also the optimal distribution of

16 dopant can be determined. Krishnamurthy et al. [42] investigated the oxygen diffusion

17 in YSZ. In the model, DFT was used to calculate the activation energies used as the

18 input of KMC. The optimum oxygen diffusivity was found can be achieved when the

19 content of $\mathrm{Y}$ is in the range of 8-12\%. Another study done by Lee et al. [43] investigated

20 the interacting energy barrier based on DFT and a KMC model. The results indicated

21 that the optimal $Y$ distribution was the microstructure in which the $Y$ ions segregate

22 into lines parallel to the conduction direction and arrange into a rectangular

23 superlattice in the perpendicular directions.

24 To sum up, the microscale modelling approaches mainly include DFT, MD and KMC.

25 The output of DFT, such as interatomic potentials and activation energies, can be 
1 employed as the input parameters of $\mathrm{MD}$ and $\mathrm{KMC}$. A series of fundamental

2 physicochemical properties, such as thermodynamics, kinetics, electrical /thermal

3 conductivity, defect formation energies, diffusion coefficient, etc., can be yielded from

4 the calculations. Microscale modelling has been becoming a powerful tool for the

5 researches of developing novel materials and obtaining optimized material structure

6 from the atomic aspect. Nevertheless, microscale modelling is limited by its simulating

7 time and length scale. The larger length scale properties like the porous structure of

8 electrodes and species transport within the electrodes are not suitable to be derived

9 from microscale modelling.

10

$11 \quad 2.2$ Mesoscale modelling

12 Mesoscale models are widely used to describe the species transport phenomena and 13 reactions in the microporous structure of electrodes [22]. Since it could provide 14 significant underlying fundamentals within electrodes, it becomes a more and more 15 important method for the development of advanced electrode structure. Since the 16 length scale and time scale of mesoscale modelling are greater than that of microscale 17 modelling, the detailed information regards to molecule motions are simplified. The 18 elementary kinetic-based electrochemistry approach, morphology-reconstruction 19 approach and Lattice Boltzmann Method (LBM), are the most widely applied 20 approaches to build mesoscale models [40].

21

\section{$22 \quad$ 2.2.1 Elementary kinetics approach}

23 Elementary kinetics provides an in-depth description of the mechanisms of 24 electrochemical reactions. The electrochemical reaction can be resolved into several 25 steps. The reaction rate constants: $\mathrm{k}_{\mathrm{f}}$ (forward) and $\mathrm{k}_{\mathrm{r}}$ (backward) describe the kinetic 


\section{4}

5

$$
\mathrm{i}=z F L_{T P B}\left[k_{f} \prod_{j}^{R_{f}} \theta_{j}^{v_{j}^{f}}-k_{r} \prod_{j}^{R_{r}} \theta_{j}^{v_{j}^{r}}\right]
$$

11 where LTPB is the TPB length; $z$ is the number of charges transferred; $\theta_{j}$ is the surface coverages of species $\mathrm{j} ; \mathrm{v}_{\mathrm{j}}$ is the stoichiometric coefficients.

Ren et al. [45] has developed a microkinetic model to investigate the mechanism of

$14 \mathrm{CO}_{2}$ reduction at the TPB of Ni/samarium-doped ceria (SDC). At first, DFT was employed to calculate the total energies of elementary reaction steps (shown in Figure 4). DFT results discovered that interface oxygen vacancy was capable of enhancing

$17 \mathrm{CO}_{2}$ adsorption and subsequent reduction by lowering its energy barrier. Two different surface models were built: model 1 was the Ni/SDC with noninterface oxygen vacancy; model 2 was the Ni/SDC with interface oxygen vacancy. It was found that the ratecontrolling step (model 1) would change from the oxygen spill-over step to the CO 21 desorption step when the overpotential at cathode experienced an increase. However, 22 it was suggested that the rate-controlling step (model 2) was the CO desorption and 23 independent of the overpotential. 


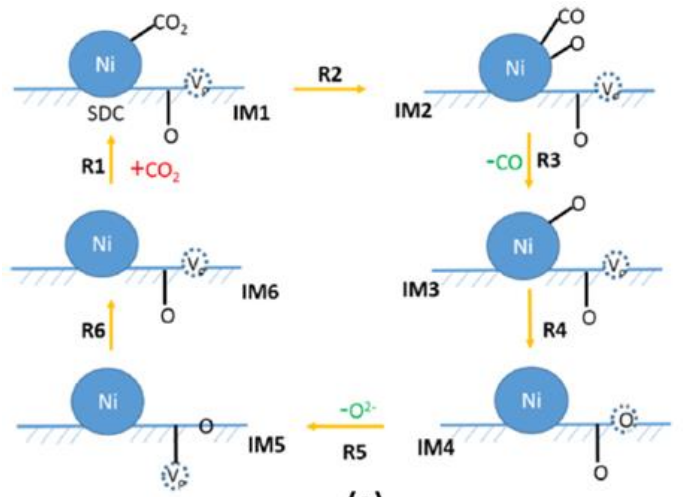

(a)

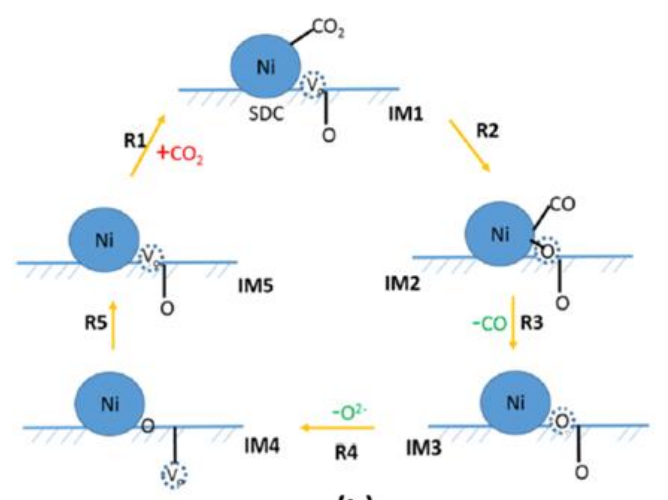

(b)

2 Figure 4 Elementary reaction steps for $\mathrm{CO}_{2}$ reduction on $\mathrm{Ni}-\mathrm{SDC}$ : (a) model 1;(b)

3 model 2. Dashed circle represents the oxygen vacancy; $R$ represents the reaction; IM

4 represents intermediate species, reproduced by permission [45], copyright 2018,

5 American Chemical Society.

6

\section{$7 \quad$ 2.2.2 Morphology-reconstruction approach}

8 Morphology-reconstruction requires detailed morphology of porous electrodes as the

9 physical boundary of the model. Generally, two steps are required in the morphology-

10 reconstruction approach: 1. generate a microstructure; 2 . simulate the transfer

11 processes within the microstructure [40]. The structure of electrodes can be

12 reconstructed by either experimental or numerical methods. The experimental reconstruction base on a series of images of the microstructure. Alternatively, the

14 numerical methods include stochastic correlation reconstruction, discrete element 15 method (DEM), and Monte Carlo (MC) method.

16 Stochastic correlation reconstruction, based on the analyses of statistical spatial 17 correlations, can be used to reproduce the 3D microstructures [46]. Moussaoui et al. 18 [47] presented a 3D model to simulate the microstructure of Lanthanum Strontium 19 Cobalt Ferrite (LSCF) and Ni-YSZ. The real microstructure morphology was 20 accomplished by using X-ray nano-tomography, while the synthetic microstructure 
1 was developed by using a 3D Gaussian 'Random Field Model'. The microstructural

2 parameters, such as tortuosity and TPB length density, were used as the target

3 indexes to govern the reconstruction process. It is found that the two-phase LSCF

4 model was able to predict the electrode microstructural architecture precisely.

5 Furthermore, the model was extended to three-phase for Ni-YSZ. Moreover,

6 stochastic modelling is capable of studying the quantitative relationship between the

7 manufacturing process and the microstructural architectures. Based on stochastic

8 modelling, Gaiselmann and co-workers [48] proposed a quantitative relationship

9 between the Lanthanum Strontium Cobaltite production processes (different sinter

10 temperatures and different pore former contents) and the corresponding final

11 microstructures.

12 DEM has been commonly applied to reconstruct the electrodes as random structures

13 consisting of ionic and electronic conductive particles [49]. DEM is an effective

14 approach to optimize the morphology of electrodes and to bridge the gap between the

15 microstructure at a particle scale and macroscopic electrode performances. The main

16 feature of DEM is to treat each particle as a discrete object and deal with the sum of

17 the contact force, which determines the motion of individual particles [50]. DEM was

18 also used to generate the microstructure of electrodes with consideration of the

19 realistic sintering process of powder packings [51]. Besides, DEM is capable of

20 investigating the mechanical properties of electrodes. Liu et al. [52] conducted a study

21 to simulate the mechanical behaviour of LSM/YSZ and NiO/YSZ under mechanical

22 loadings. The elastic properties of the electrodes were evaluated. Moreover, DEM has

23 been used to calculate the resistance and the effective conductivity of the electrodes

$24[53,54]$.

$25 \mathrm{MC}$ method is an alternative numerical option to generate the microstructure. Tabei et 
1 al. [55] applied a modified MC to yield the 3D microstructure of Ni/YSZ. The

2 computational microstructure showed a good agreement with the real ones. The finite

3 element method was applied to characterize the mechanical and thermal properties of

4 the reconstructed electrode. Yan et al. [49] proposed a model to study the role of

5 powder morphology in affecting the final microstructure of LSCF. DEM was used to

6 simulate the powder packing, while the output of the DEM (numerical structural

7 samples with different particle morphologies) can be obtained, which acted as inputs

8 of $\mathrm{KMC}$ to simulate the powder sintering (shown in Figure 5).

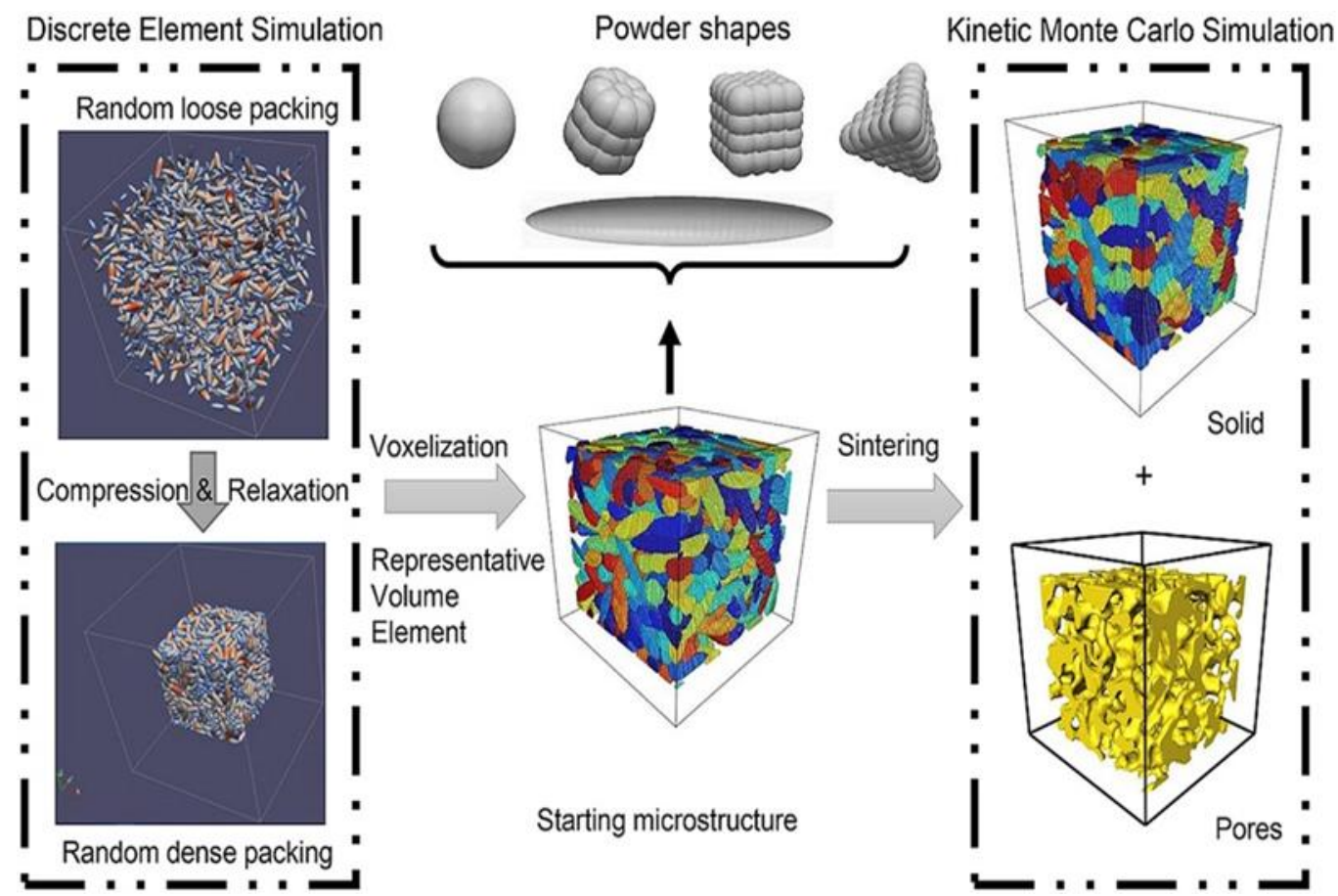

10 Figure 5 A morphology-reconstruction model, reproduced by permission [49], 11 copyright 2017, Elsevier.

\subsubsection{Lattice Boltzmann Method (LBM)}

14 LBM is a promising computational fluid dynamics (CFD) approach that is capable of 15 simulating mass transport over a wide range of Knudsen numbers in the porous 16 electrodes through considering the non-continuum effects, complex geometries and 17 multiple species [56]. 
1 The simulation region in LBM is regarded as a lattice system, where the particle moves

2 from site to site. The most significant difference between LBM and MD is that LBM

3 calculates the particle velocities distribution function (PDF) other than the positions

4 and velocities of the particles [41]. The PDF $f_{\alpha}^{i}$ at any lattice point $x$ and time $t$ is

5 proportional to the moles of each species $i(=1,2,3, \ldots)$ presented at $x$ with a velocity

$6 e_{\alpha}^{i}$ along a specific direction a [56]. An LBM process includes two basic steps:

7 streaming and collision. In streaming, the particles of $i$ with $e_{a}^{i}$ at $x$ stream to

8 neighbouring points, and the collision represents the interactions between particles

9 arriving at that the lattice point from neighbouring points (of the same or different

10 species) [56]. The lattice Boltzmann equation is given by combining the streaming and 11 collision steps:

$$
f_{\alpha}^{i}\left(\mathrm{x}+\mathrm{e}_{\alpha}^{\mathrm{i}}, \mathrm{t}+1\right)=\mathrm{f}_{\alpha}^{\mathrm{i}}(\mathrm{x}, \mathrm{t})+\Omega_{\alpha}^{\mathrm{i}}
$$

13 where $\Omega_{\alpha}^{i}$ is the collision term. Therefore, some macroscopic properties such as 14 velocities, densities can be calculated from resolving the moments of $f_{\alpha}^{i}$ over velocity 15 space $[41,57]$. The complex microstructure provided by morphology-reconstruction 16 models could be employed as the physical boundaries of LBM model (shown in Figure 17 6). 


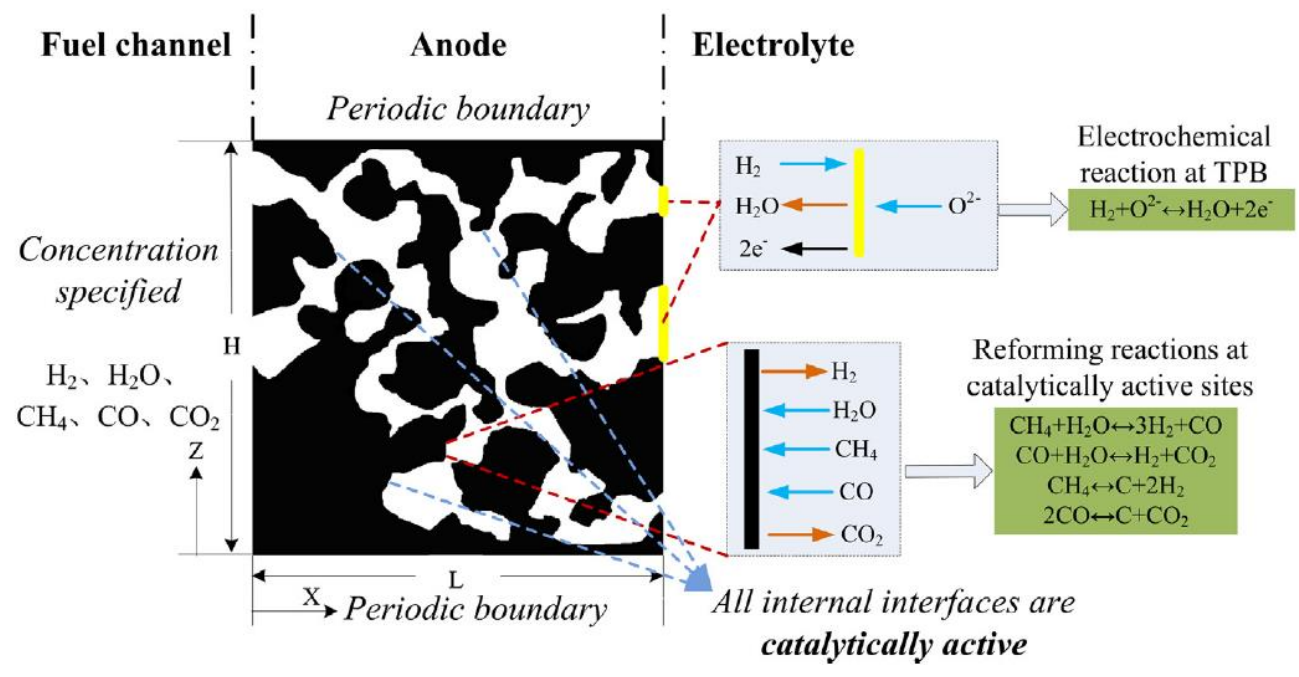

2 Figure 6 Schematic of the simulation domain and physical boundaries of LBM model,

3 reproduced by permission [58], copyright 2016, Elsevier.

\section{$5 \quad 2.3$ Macroscale modelling}

\section{$6 \quad$ 2.3.1 Cell-level modelling}

7 The principal objectives of cell-level modelling are the transfer processes, including

8 mass, heat and charge transfer, and chemical/electrochemical reactions in the SOEC

9 [22]. CFD is a powerful research tool to resolve the distribution of physicochemical

10 processes based on conservation equations of mass, energy and momentum, and

11 reaction kinetics. Commercial software such as COMSOL and FLUENT and open-

12 source platforms like OpenFOAM are available to resolve the governing equations.

13 In cell-level modelling, the continuum approach is often applied, which treats the 14 porous materials and medium filling in the pores as a homogenized continuum [40].

15 Continuum approach gives a complete description of transfer processes in the 16 electrodes. The modelling based on the continuum approach strongly relies on the 17 effective microstructure parameters such as porosity and permeability. Besides, the 18 electrochemistry in the SOEC is also investigated at a continuum-level. It is based on 
1 the Nernst equation and the polarizations of the SOEC.

$$
\begin{aligned}
& \mathrm{E}=E_{0}+\frac{\mathrm{RT}}{n F} \ln \left(\frac{\prod a_{\text {products }}^{v_{i}}}{\prod a_{\text {reactants }}^{v_{i}}}\right) \\
& \mathrm{V}=\mathrm{E}+\eta_{\text {act }}+\eta_{\text {conc }}+\eta_{\text {ohmic }}
\end{aligned}
$$

4 where $E$ is the equilibrium voltage; $E_{0}$ is the standard potential; $R$ is the universal gas

5 constant; $n$ is number of electrons transferred; $a$ is the activity of the species; $\eta$ is the

6 polarization (activation, concentration and ohmic) of the cell; $\mathrm{V}$ is the external voltage.

7 Generally, the activation overpotential is usually determined by the Butler-Volmer 8 equation $[59,60]$ :

$$
\mathrm{i}=i_{0}\left[\exp \left(\frac{\alpha n F \eta_{a c t}}{R T}\right)-\exp \left(-\frac{(1-\alpha) n F \eta_{a c t}}{R T}\right)\right]
$$

Where $i$ is the current density; io is the exchange current density; $\alpha$ is the charge transfer coefficients. However, it is worth mentioning that the Butler-Volmer equation may not be the most suitable equation to describe the activation overpotential. In some studies, a modified Bulter-Volmer equation was applied $[61,62]$. The concentration overpotential is caused by the diffusion losses in the SOEC. The mass transport through porous media can be explained by the multi-component gas transport models. For example, Fick's model (FM) is the simplest model, whereas, FM cannot be used when the molecular weights of gas species vary significantly [63]. It was found that cathode is more susceptible to concentration overpotential. Stefan-Maxwell model (SMM) accounts for the molecular weights, however, the effects of Knudsen diffusion is ignored [63]. Dusty-Gas model (DGM) can be considered as an extension of SMM 21 that takes into account Knudsen diffusion:

$$
\sum_{j=1, j \neq i}^{n} \frac{y_{j} \mathbf{N}_{i}-y_{i} \mathbf{N}_{j}}{D_{i j, B}^{\text {eff }}}+\frac{\mathbf{N}_{i}}{D_{i, k}^{\text {eff }}}=-\frac{1}{R T}\left(P \frac{\mathrm{d} y_{i}}{\mathrm{~d} z}+y_{i} \frac{\mathrm{d} P}{\mathrm{~d} z}\left(1+\frac{K_{0} P}{D_{i, k}^{\mathrm{eff}} \mu}\right)\right)
$$

23 Where $\mathrm{Ni}_{\mathrm{i}}$ is the molar diffusion flux of species $\mathrm{i}$; yi represents the molar fraction of 
1 species $i ; D_{i, i}^{\text {eff }}$ is the effective binary diffusion coefficient, $D_{i, k}^{\text {eff }}$ is the effective Knudsen

2 diffusion coefficient; $\mathrm{P}$ is the pressure. Considering the simplicity and computational

3 cost, FM and SMM are usually applied in the literature [64,65]. On the other hand, in

4 order to realize a more precise description of mass transfer in porous electrodes, DGM

5 has been used by many groups in the modelling studies as well $[66,67]$. The ohmic

6 overpotential is typically described by Ohm's law [68].

7 Cell-level models can combine the continuum approach with the elementary kinetics

8 approach to simulate the mass/charge transports coupling with a more precise

9 electrochemistry. Grondin et al. [61] developed a 1D model to simulate the cathodic

10 behaviour of Ni-YSZ. This model offered a description of mass and charge transports

11 in the cathode. The elementary kinetics approach was used to investigate two different

12 electrochemical reaction mechanisms of $\mathrm{H}_{2} \mathrm{O}$ electrolysis, which concluded that the

13 adsorption process of $\mathrm{H}_{2} \mathrm{O}$ has a significant effect on modelling results. An elementary

14 reaction-based model was proposed to predict the SOEC behaviour for $\mathrm{CO}_{2}$ reduction

15 by Shi and co-workers [69]. An elementary reaction model, which adopted a

16 heterogeneous mechanism, was established to understand adsorption/desorption

17 reaction kinetics on the catalytic surface. It also took into account the carbon

18 decomposition, which can damage the cell structure and reduce the performance of

19 SOEC. The modelling results showed that the major elemental species were (Ni) and

$20 \mathrm{CO}(\mathrm{Ni})$. Operating SOEC at a high temperature condition can is favourable for $\mathrm{CO}_{2}(\mathrm{Ni})$

21 consumption and $\mathrm{CO}$ production. It also indicated that the possibility of carbon

22 decomposition could be mitigated at a low CO level. Menon et al. [62] developed a

23 model to simulate the SOEC operation during co-electrolysis. The impacts of

24 microstructural properties (such as porosity and tortuosity) and operating conditions

25 (such as temperature and inlet gas velocity) on the syngas ( $\mathrm{H}_{2}$ and $\mathrm{CO}$ ) production 
1 were explored by this model. By using the elementary kinetics approach, a detailed

2 reaction mechanism on $\mathrm{Ni}$ catalyst, which took into account the reverse water gas shift

3 reaction (RWGSR) and methanation reaction (MR), was applied to conduct a

4 parametric analysis. It was found that increasing the input of $\mathrm{CO}_{2}$ cannot enhance the

5 MR, whereas the increase in the $\mathrm{H}_{2} \mathrm{O}$ hindered the MR. Additionally, a most likely

6 reaction pathway of MR was determined in their study.

7 Cell-level models provide a good comprehension of the performance of the cell at

8 various operation conditions, which can be used to provide guidelines for optimization

9 design. $\mathrm{Ni}$ [70] proposed $1 \mathrm{D}$ and $2 \mathrm{D}$ models for $\mathrm{CO}_{2}$ electrolysis to study the

10 comprehensive reaction-transfer phenomena. Li et al. [64] developed SOEC models

11 for co-electrolysis to study the competitive effect between electrochemical and

12 chemical reactions. The modelling results suggested that the rate of heterogeneous

13 chemical reactions was faster than that of electrochemical reactions. Moreover, it was

14 found that the cathode thickness posed a significant influence on the active sites for

15 reactions. CFD model was also used to optimize the gas distribution in solid oxide

16 devices [71]. A further study [72] suggested that the structure parameters, material 17 performance, and gas composition could remarkably influence the zone sizes of 18 heterogeneous reaction electrochemical reactions. Du et al. [73] developed a 3D 19 model of SOEC to study the effect of operation pressure on co-electrolysis of water 20 and carbon dioxide. Optimal operation conditions were proposed and counter-flow 21 arrangement is found a better configuration than co-flow.

22 The degradation of electrodes caused by thermal stress and strains is a challenging 23 problem that the SOEC is facing. Jin and Xue [74] presented a 2D CFD model to study 24 the delamination phenomenon at the anode-electrolyte interface. It is found that the 25 delamination of the electrode and electrolyte significantly impacts the distribution of 
1 current density. Moreover, the SOEC performance was more sensitive to the

2 delamination occurred at the central area of the cell than at the edges. Nerat et al. [75]

3 proposed another model to study the delamination of SOEC in long-term operation.

4 The anode delamination was modelled by modifying the geometry of the cell (shown

5 in Figure 7 (a)). It was concluded that the increase of the delaminated area at anode

6 could be the main reason causing the efficiency drop of SOEC in the long term. A 3D

7 model was proposed by Navasa et al. [76] to investigate local conditions (i.e., gas

8 composition, potentials and temperature) that can result in cell degradation. In

9 particular, the authors simulated the conditions in the electrodes, and generated an

10 accurate description of the spatial variations of these factors through the electrodes.

11 Moreover, the impacts of thermal boundary conditions on cell performances were also

12 explored aiming at extending the lifetime of SOEC.

13 A recent study shows that the use of low-cost fuels reacting with $\mathrm{O}_{2}$ at the anode can

14 reduce the operating potential of SOEC as well as the electricity demand [77]. This

15 type of SOEC is also known as 'fuel-assisted SOEC (SOFEC)'. Luo et al. [78]

16 developed a 1D SOFEC model. This model contained a mesoscale sub-model to

17 simulate the elementary reactions on the catalyst surface. The elementary reactions

18 modelling results revealed the reason why $\mathrm{CH}_{4}$-assisted SOFEC performed better

19 than the CO-assisted SOFEC. The results indicated that carbon deposition was a

20 critical problem in $\mathrm{CH}_{4}$-assisted SOFEC. Xu et al. [79] developed a 2D $\mathrm{CH}_{4}$-assisted

21 SOFEC model, including an electrochemical module (describing overpotentials), a

22 CFD module (simulating mass/heat transfer) and a chemical module (studying the

23 RWGSR and steam methane reforming reaction). The results suggested that the effect

24 of the anode gas flow rate on cell performance was significant, which was quite

25 different from the behaviour of conventional SOEC. 
1 Furthermore, the results from cell-level modelling can provide useful information given

2 to stack or system operation. Zhang et al. [80] developed a 1D model of SOEC for

$3 \mathrm{CO}_{2}$ reduction. Based on the results, five different design strategies of a SOEC system

4 for $\mathrm{CO}_{2}$ electrolysis were proposed.

5 To summarize briefly, cell-level modelling is a useful approach to simulate the

6 operation of a single cell. The results from mesoscale modelling can be applied as

7 inputs in cell-level modelling. However, cell-level modelling only considers a single

8 SOEC cell under a laboratory scale. To bring SOEC into the commercial market, unit

9 SOEC cells should be integrated into a SOEC stack to meet the practical requirements.

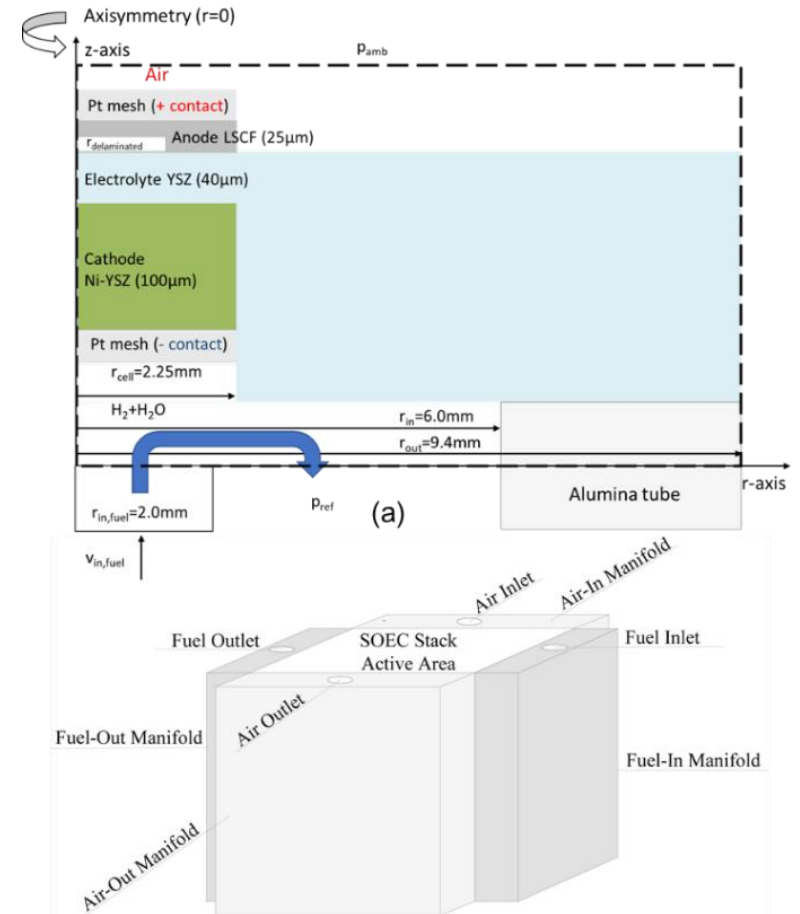

(b)

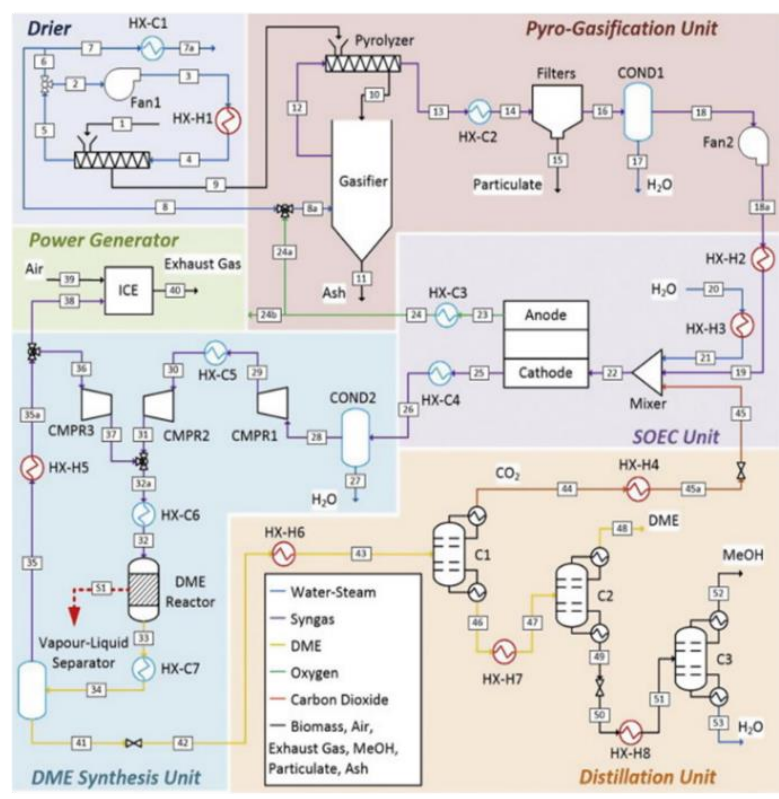

(c)

11 Figure 7 Schematic of (a) a 2D SOEC model with partly delaminated anode, reproduced by permission [75], copyright 2018, Elsevier; (b) geometry of a 3D SOEC stack model, reproduced by permission [81], copyright 2019, Elsevier; (c) a novel system design, reproduced by permission [82], copyright 2015, Elsevier. 


\section{$1 \quad$ 2.3.2 Stack-level modelling}

2 Stack-level models simulate the behaviour of the SOEC stack, which consists of

3 multiple cells, interconnects, manifolds, seals, and cell frames [22]. Stack-level models

4 provide a comprehensive description of stack operations and give valuable insights

5 into how to optimize the stack performance by changing the operating strategy or the

6 stack design. Additionally, it can serve as design guidelines to eliminate the uneven

7 distribution of species and temperature within the stack and maximize the power of

8 the SOEC stack. CFD can also be a computational tool to explore the transport

9 processes within the stack. The electrochemistry of the SOEC stack is developed at a

10 continuum-level. Since the geometry of the SOEC stack is far more complicated than

11 that of a single SOEC, the resolution of stack-level modelling often relies on the simplification assumption [40], which sacrifices some information in the cell-level.

Therefore, a concept of single repeat unit (SRU), i.e., a cell coupled with other auxiliary components, is introduced [83]. First, the transport and electrochemistry properties of SRU are described at the cell-level. Then, a SOEC stack with a large number of equivalent SRUs is simulated to build the stack-level model. Such a method illustrates the relationship between cell-level and stack-level with the computational cost for stack-level modelling can be dramatically reduced.

Hawkes et al. [84] proposed a 3D model of a SOEC stack to investigate the effect of operating conditions on the stack performance. The effects of different operating voltages on the temperature, operating potential, current density, anode/cathode side gas composition were evaluated. Laurencin and co-workers [85] proposed a 2D model, including both electrochemical (studying overpotential and local current density) and

24 thermal modules (simulating the thermo fluid and temperature field) of SOEC. The 25 simulation suggested that the thermal equilibrium was intensively dependent on the 
1 radiative heat losses.

2 Keeping the mechanical integrity is a tough task in stack operation. In the long-term

3 operation, deformation and material failure caused by the thermo stresses can result

4 in hot spots, accelerating thermal mismatch and eventually cause leak problem and

5 performance decline. Therefore, it is essential to achieving a uniform temperature

6 distribution within the stack. Udagawa et al. developed a 1D model for a SOEC stack

7 operating at a steady/dynamic state [86-88]. The influences of temperature and

8 current densities under exothermic/endothermic operations were investigated. The

9 impacts of airflow rates on temperature were investigated. A potential temperature

10 control strategy was proposed to prevent the fracture of cell components. Xu et al. [81]

11 developed a 3D model to simulate the influence of operating mass flow rates on the

12 behaviour of a SOEC stack (shown in Figure 7 (b)). The performances of cells in

13 different layers of the stack were investigated. The authors discussed the distribution

14 of pressure, temperature, and fluid flow under different operating gas flow rates. Stack-

15 level models have been used to study the degradation issues as well as determine the

16 operating strategy for mitigating the degradation. Molla et al. [89] developed a model

17 to study the stresses in different design configurations and the effects of temperature

18 distribution. It was found that delamination can be caused by stress reversal in over

19 rigid stack design. Furthermore, it was indicated that much lower stress and

20 temperature gradients can be achieved through convection cooling than conduction.

21 In order to increase the computational speed of the stack-level model, Navasa et al.

22 [90] proposed an original stack model with a low computational cost. Such advantages

23 are attributed to so-called homogenization, which substitutes the repeating unit with

24 an equivalent homogeneous medium. The authors took a further step to increase the

25 computational efficiency by applying the homogenization to the whole repeating unit. 
1 Hereby, compared with conventional models, the simulating time of this model can be

2 mitigated by two orders of magnitude. Additionally, the researchers pointed out that

3 further modelling studies can focus on explicitly representing the local details and

4 maintaining the high computation efficiency at the same time.

5 In practice, the stack is an essential element in a solid oxide plant which can work in

6 electrolysis mode to store the electrical energy into hydrogen or in a fuel cell model to

7 generate electricity [91]. The behaviour of the stack in real practice can be investigated

8 by modelling, subsequently generating the optimal stack design and operation

9 strategies. Wang et al. [92] introduced a novel dynamic stack-level model which

10 extensively studied the various designing and operating factors (temperature,

11 pressure, heat capacity, current density, fuel fraction and mode switching frequency)

12 on the performance of the stack during switching processes. According to their

13 modelling results, to extend the lifetime of the stack, it is advisable to increase the heat

14 capacity of the stack and inlet hydrogen molar fraction. Additionally, increasing the

15 operating pressure and decreasing the current density is favourable to improve the 16 reversible efficiency.

\subsubsection{System modelling}

19 System-level modelling takes the entire SOEC system into account. SOEC system 20 consists of SOEC stacks and the balance of plant (BoP) components like pumps and $21 \mathrm{ac} / \mathrm{dc}$ converter $[22,93]$. The primary purpose of system-level modelling is to maximize 22 the overall efficiency of the system by optimizing the system design and operating 23 strategies. The system-level model is not intended to understand the detailed stack 24 behaviour, but to use the output of stack-level sub-model to investigate the interaction 25 between stack and BoP. However, the interactions between the cells within the stack, 
1 and between the stack and BoP are complex. Thus, the in-situ system-level modelling

2 to simulate the real-time operation is costly. To address this issue, the simplification

3 of the geometry of sub-models, such as BoP models, is often applied in system-level

4 modelling [22]. The process simulator, also known as flowsheeting software, can be

5 employed to construct a system-level model. Flowsheeting can be broadly defined as

6 a systemic description of material and energy streams in a system with the aid of

7 computer simulation [94]. Several commercial process simulators are available for

8 system-level modelling, such as ASPEN and SIMULINK [95].

9 System-level modelling is an economical approach to find the optimal operating 10 schemes to maximize overall efficiency. This is often accomplished by analysing the 11 thermodynamic of the system, with the aid of first/second laws of thermodynamics. 12 Both energy and exergy analyses can be included in the thermodynamic modelling of 13 the SOEC system. Ni et al. [96] developed a system-level model to conduct the 14 energy/exergy analyses and corresponding efficiency calculations. The effects of 15 operating conditions on the efficiency were investigated as well. It was found that 16 energy/exergy efficiency can be maximized through adapting the current density, the 17 gas velocity, and operating temperature. Mingyi et al. [97] proposed a thermodynamic model concerning the efficiencies of the SOEC system. The model explored the impacts of three essential parameters (electrical efficiency, thermal efficiency, and 20 electrolysis efficiency) on the overall energy efficiency. Stempien et al. [98] carried out 21 a thermodynamic model to simulate the effects of operating parameters on system performance. With the aid of energy and exergy analysis, the optimal operating voltage of the system was determined.

24 In order to develop an economical SOEC for commercial promotion, it is essential to 25 carry out a techno-economical assessment to assess the economic performance of 
1 the system. Such an assessment is useful to evaluate the economic feasibility and

2 future commercialization potential of the system. In addition, the techno-economical

3 assessment can be used as a guide tool to optimize the operating strategies for

4 minimizing the operating/capital cost. Samavati et al. [99] presented a system-level

5 model for syngas production. A thermodynamic sub-model, including energy and

6 exergy analyses, was developed. The economic analyses indicated that the electricity

7 price showed the largest contribution to the final cost of reduction products. Rivera-

8 Tinoco et al. [100] assessed a system coupling water electrolyser (either PEMEC or

9 SOEC) with a $\mathrm{CO}_{2}$ reactor to produce methanol. The $\mathrm{H}_{2}$ produced from water

10 electrolysis was transferred to a $\mathrm{CO}_{2}$ reactor to generate methanol. The techno-

11 economic assessment demonstrated that the SOEC approach was more capital-

12 consuming, whereas the PEMEC option expensed more on operation cost. Buttler et

13 al. [101] performed a techno-economical assessment of a SOEC system with heat

14 integration on the basis of a high temperature electrolysis plant. The results illustrated

15 that the high temperature electrolysis plant with heat integration was economically

16 feasible. Furthermore, an extensive sensitivity analysis demonstrated the

17 positive/negative influential factors of the application of heat integration.

18 System-level models have been used to evaluate the feasibility of a novel system 19 design. For a given design problem, a new proposed system configuration can be 20 assessed through simulating and integrating the individual units of the system. Pozzo 21 et al. [82] presented a novel system design to enhance the dimethyl ether (DME) 22 production. The system, combining a woody biomass gasifier and a SOEC unit, was 23 modelled by ASPEN (shown in Figure 7 (c)). Pinch analysis was performed for the 24 whole system. Furthermore, it was found that the overall efficiency and specific 25 productivity of the novel plant were much higher than that of the conventional design. 
1 SOEC is a pivotal component in Power-to-Gas systems. Such systems have a great

2 potential in storing excess electrical energy into energy carriers such as $\mathrm{H}_{2}\left(\mathrm{via} \mathrm{H}_{2} \mathrm{O}\right.$ 3 electrolysis/co-electrolysis) and CO (via co-electrolysis) [102,103]. By further 4 processing, the produced gases can be easily converted into methane, methanol, 5 DME and gasoline [102]. Techno-economic viability and lifespan are two main 6 challenges to such system operation. System-level models can simulate the system 7 operation and provide an optimal system design as well as a long-term operating 8 strategy. Wang et al. [104] established a model to investigate several essential 9 designing issues, including system-level heat integration, the effects of operating 10 conditions and the avoidance of electrical heating. Based on the modelling results, for 11 both $\mathrm{H}_{2} \mathrm{O}$ electrolysis and co-electrolysis, it was found that high system efficiency and 12 high methane production cannot be achieved at the same time. Besides, the SOEC 13 was found to be more favourable operating at exothermic mode other than 14 thermoneutral mode, as that operation improves the flexibility and reliability of the 15 system. Another model proposed by Wang et al. [105] aims to assist the design of a 16 co-electrolysis-based power-to-methane system. In the study, the requirements for 17 maximizing the methane production and the impacts of pressurized operation and 18 internal methanation were investigated. It was found that the dominating reaction of 19 co-electrolysis was $\mathrm{H}_{2} \mathrm{O}$ splitting while $\mathrm{CO}_{2}$ was reacted via RWGSR. The internal 20 methanation can be used as an effective internal heat source to sustain the 21 temperature, which allows the co-electrolysis-based system to obtain a higher 22 efficiency than the $\mathrm{H}_{2} \mathrm{O}$ electrolysis-based system.

23 Moreover, hybrid energy hub, a promising concept for integrated management of 24 energy systems, can be broadly defined as a framework where various energy carriers 25 can be produced, converted, stored and consumed in order to satisfy energy demands 
1 [106,107]. Energy hub can be divided into different microgrids regarding its

2 consumption region (such as commercial and residential). It can not only offer low-

3 cost sustainable and clean energy but also enhance the resiliency and stability of local

4 grid [107]. Nevertheless, due to the complexity of both information exchange within

5 the energy hub and the relationships between different units, system-level modelling

6 is required to provide a more accurate description of energy hub behaviours and

7 optimize its operations. Parisio et al. [108] used a robust optimization approach to

8 develop a system model of an energy hub. The aim of this model is to satisfy the time-

9 varying energy output demands while minimise energy costs. Their work obtained a

10 robust operation schedule for the energy hub. Hutty et al. [109] introduced a system

11 model to simulate the operation of a microgrid composing of houses coupling with the

12 solar photovoltaic unit and SOEC/battery. The model was used to optimize the size of

13 units of the microgrid and quantify the self-sufficiency ratio. They also did the case

14 studies for UK and Texas, and found that the hybrid energy storage system (SOEC

15 with battery) is superior to the battery-only system when the self-sufficiency ratio of

16 the system was given at a high level. Colombo and co-workers developed a system

17 model of the campus microgrid to simulate existing power plant behaviours and

18 investigate the response of a microgrid to additional renewable installed capacity [110].

19 In this model, a SOEC system was included and showed a good performance in

20 storing the excess renewable capacities of the microgrid. Rispoli et al. [111] proposed

21 another system model of SOEC-based microgrid to optimize the microgrid sizing as

22 well as the year-around energy management. A techno-economic study was

23 conducted to determine the optimal grid configuration by applying a constrained

24 design method. It was found that the payback period for this SOEC-based microgrid

25 was reasonable. This model can serve as a basis for the optimal design of microgrids 
1 as well as the operation strategies.

\section{3. Perspectives}

5 Lots of research efforts have been paid on the multiscale numerical study of SOEC

6 from microscale to system level. However, most of these studies perform different

7 length scales separately, which is known as the hierarchical method [112]. While the

8 modelling approach of performing concurrent multiple scale modelling methods is still

9 lack of investigation. In the concurrent modelling approach, detailed information in 10 multiple length scales is included in a single model, and the calculation should only be 11 carried out once [112]. However, it could require much more computation power than 12 the hierarchical method. Therefore, the priority is to balance the computation ability 13 and calculation accuracy. One of the challenges is how to apply the numerical results 14 from the bottom scale into the upper scale to achieve multiscale modelling. The shorter 15 length scale brings in higher information density. As a result, due to the limitation of 16 calculation capability, it is costly and even impossible to retain detailed information 17 from the bottom level. Strategies are needed to extract and keep the most valuable results with reasonable tolerance. As reviewed in the paper, homogenization is a commonly used strategy to represent the calculated value with an average value.

20 However, this approach is not suitable for the data with a large gradient, which could 21 lose valuable details. One practical solution to bridge CFD modelling and system simulation is provided in a commercial software package, gProms [113]. The 'multizonal modelling' strategy can be employed to divide CFD calculation domain into several zones within which the characteristics and distributions are similar. Therefore, parameters within the individual zones can be treated as constant. The concept is 
1 similar to discretisation, and is expected to balance the need of accuracy and

2 calculation cost.

3 Algorithms should be developed to treat and simplify the calculation results generated

4 from bottom scale models, which will be provided as inputs to the upper scale model.

5 During this process, the decision-making strategy is crucial to balance detailed

6 information and numerical efficiency. Data-driven artificial intelligence could be a

7 powerful tool assisting us in establishing such strategies.

8 In addition to the multi-length scale modelling, another challenge is multi-time scale 9 modelling. Compared with multi-length scale modelling, multi-time scale modelling has 10 long been overlooked and is more challenging. Modelling in multiple time scales 11 presents dynamic behaviours of transport processes and the transient response corresponding performance of SOEC, which provides guidelines for system control under start-up and fluctuant conditions. Multi-time scale modelling has been applied 14 in Solid Oxide Fuel Cell (SOFC), which can definitely be extended to SOEC $[114,115]$. 15 Moreover, multi-time scale modelling is expected to provide critical information for 16 understanding the micromorphology change and material degradation, and their long17 term effects on the SOEC performance evolution. At the same time, a large scale of long-term experimental data is needed to establish reliable correlations of material components and micromorphology.

20 In recent years, the Jiao Group has developed novel '3D+1D' or '2D+1D' multiscale 21 modelling frameworks to integrate sub-models with different dimensions for the 22 purpose of fast and economical large-scale simulation of electrochemical systems $23[116,117]$. In these frameworks, the 3D/2D sub-models are used to describe the 24 computational domains in which the parameters distribute with a large gradient in the 25 volume, while the 1D sub-models are applied in other domains. Different from the 
1 previous multiscale modelling methods focusing on the coordination of length, this

2 strategy brought a new perspective emphasing dimension combination which can also

3 be used in the study of SOEC to achieve time and cost effective modelling.

4

5 4. Conclusion

6 The working principles of SOEC for various electrolysis modes are introduced in this

7 review. The numerical modelling approaches focus on different length scales are

8 summarized accompanying recent numerical SOEC researches from microscale

9 modelling to system simulation for understanding the reaction kinetics, mass and

10 charge transfer phenomena, and obtaining optimal system operation. The attempts to

11 perform multiscale modelling of SOEC were reviewed, indicating the current

12 development of multiscale modelling is still dominated by the hierarchical method.

13 Concurrent multiscale modelling is lack of investigation. Limitations and the future

14 perspectives of multiscale modelling of SOEC are also discussed. The challenges lie

15 in bridging sperate length scale models and establishing multi-time scale modelling

16 methods. The development of modelling methodologies will continuously support the

17 advance of SOEC.

19 Acknowledgement

20

21 The authors acknowledge the Newton Advanced Fellowship supported by the Royal

22 Society (grant No. NAF\R1\180146) and support from The Engineering and Physical

23 Sciences Research Council (EPSRC) under grant number EP/V011863/1. The

24 authors also acknowledge the support from publishers to grant copyright permissions

25 of reproduced materials in the paper. 


\section{$1 \quad$ References}

2 [1] The Climate Change Act 2008 (2050 Target Amendment) Order 20192019.

[2] $2050 \quad$ long-term

strategy

Climate Action

2019. https://ec.europa.eu/clima/policies/strategies/2050_en.

[10] Bertuccioli L, Chan A, Hart D, Lehner F, Madden B, Standen E. Development of

[8] Keçebalcs A, Kayfeci M, Bayat M. Electrochemical hydrogen generation. Sol.

[6] Lehner M, Tichler R, Steinmüller H, Koppe M. Power-to-gas: technology and business models. Springer; 2014.

[7] Carmo M, Fritz DL, Mergel J, Stolten D. A comprehensive review on PEM water electrolysis. Int J Hydrogen Energy 2013;38:4901-34. water electrolysis in the European Union. Fuel Cells Hydrog Jt Undert 2014;83.

[11] Wachsman ED, Lee KT. Lowering the temperature of solid oxide fuel cells. 
Science (80- ) 2011;334:935-9. https://doi.org/10.1126/science.1204090.

[12] Laguna-Bercero MA. Recent advances in high temperature electrolysis using solid oxide fuel cells: A review. J Power Sources 2012;203:4-16. https://doi.org/10.1016/j.jpowsour.2011.12.019.

[13] Ghezel-Ayagh H. Modular Solid Oxide Electrolysis Cell System for Efficient Hydrogen Production at High Current Density. 2018.

[14] Reytier M, Di lorio S, Chatroux A, Petitjean M, Cren J, De Saint Jean M, et al. Stack performances in high temperature steam electrolysis and co-electrolysis. Int J Hydrogen Energy 2015;40:11370-7.

[15] Jun A, Kim J, Shin J, Kim G. Achieving high efficiency and eliminating degradation in solid oxide electrochemical cells using high oxygen-capacity perovskite. Angew Chemie Int Ed 2016;55:12512-5.

[16] Abbaspour A, Nandakumar K, Luo J, Chuang KT. A novel approach to study the structure versus performance relationship of SOFC electrodes. J Power Sources 2006;161:965-70.

[17] Khan ME, Khan F, others. A comparative study of white box, black box and grey box testing techniques. Int J Adv Comput Sci Appl 2012;3.

[18] Milewski J, Świrski K, Santarelli M, Leone P. Advanced methods of solid oxide fuel cell modeling. Springer Science \& Business Media; 2011.

[19] Stempien JP, Sun Q, Chan SH. Solid Oxide Electrolyzer Cell Modeling: A Review. J Power Technol 2013;93:216-46.

[20] Wang K, Hissel D, Péra MC, Steiner N, Marra D, Sorrentino M, et al. A Review on solid oxide fuel cell models. Int J Hydrogen Energy 2011;36:7212-28. https://doi.org/10.1016/j.ijhydene.2011.03.051.

[21] Tulleken HJAF. Grey-box modelling and identification using physical knowledge 
and Bayesian techniques. Automatica 1993;29:285-308.

[22] Stolten D, Emonts B. Fuel Cell Science and Engineering, 2 Volume Set: Materials, Processes, Systems and Technology. vol. 1. John Wiley \& Sons; 2012.

[23] Gross EKU, Dreizler RM. Density functional theory. vol. 337. Springer Science \& Business Media; 2013.

[24] Ullrich CA. Time-dependent density-functional theory: concepts and applications. OUP Oxford; 2011.

[25] Martinez TJ. Seaming is believing. Nature 2010;467:412-3.

[26] Hafner J. Ab-initio simulations of materials using VASP: Density-functional theory and beyond. J Comput Chem 2008;29:2044-78.

[27] Jiang SP. Nanoscale and nano-structured electrodes of solid oxide fuel cells by infiltration: Advances and challenges. Int J Hydrogen Energy 2012;37:449-70. https://doi.org/10.1016/j.ijhydene.2011.09.067.

[28] Rashkeev SN, Glazoff M V. Atomic-scale mechanisms of oxygen electrode delamination in solid oxide electrolyzer cells. Int $\mathrm{J}$ Hydrogen Energy 2012;37:1280-91.

[29] Cadi-Essadek A, Roldan A, de Leeuw NH. Stability and mobility of supported Nin ( $n=1--10)$ clusters on ZrO2 (111) and YSZ (111) surfaces: a density functional theory study. Faraday Discuss 2018;208:87-104.

[30] Morin J, Pelletier JM. Density Functional Theory: Principles, Applications and Analysis. Nova Science Publishers, Incorporated; 2013.

[31] Cadi-Essadek A, Roldan A, Aparicio-Anglès X, de Leeuw NH. CO2 and H2 Adsorption and Reaction at Ni n/YSZ (111) Interfaces: A Density Functional Theory Study. J Phys Chem C 2018;122:19463-72. 
1 [32] Sun $\mathrm{Y}$, Wang $\mathrm{C}$, Chen $\mathrm{Y}$. Molecular dynamics simulations of the deformation behavior of gadolinia-doped ceria solid electrolytes under tensile loading. $\mathrm{J}$ Power Sources 2013;233:131-8.

[33] Gunn DSD, Purton JA, Metz S. Monte Carlo simulations of gadolinium doped ceria surfaces. Solid State lonics 2018;324:128-37.

[34] Marx D, Hutter J. Ab initio molecular dynamics: basic theory and advanced methods. Cambridge University Press; 2009.

[35] Voter AF. Introduction to the kinetic Monte Carlo method. Radiat. Eff. solids, Springer; 2007, p. 1-23.

[36] Brinkman HW, Briels WJ, Verweij H. Molecular dynamics simulations of yttriastabilized zirconia. Chem Phys Lett 1995;247:386-90.

[37] Li X, Hafskjold B. Molecular dynamics simulations of yttrium-stabilized zirconia. J Phys Condens Matter 1995;7:1255.

[38] Inaba H, Sagawa R, Hayashi H, Kawamura K. Molecular dynamics simulation of gadolinia-doped ceria. Solid State lonics 1999;122:95-103.

[39] Schelling PK, Phillpot SR. Mechanism of Thermal Transport in Zirconia and Yttria-Stabilized Zirconia by Molecular-Dynamics Simulation. J Am Ceram Soc $2001 ; 84: 2997-3007$.

[40] Ni M, Zhao TS. Solid oxide fuel cells: from materials to system modeling. Royal Society of Chemistry; 2013.

[41] Satoh A. Introduction to practice of molecular simulation: molecular dynamics, Monte Carlo, Brownian dynamics, Lattice Boltzmann and dissipative particle dynamics. Elsevier; 2010.

[42] Krishnamurthy R, Yoon Y-G, Srolovitz DJ, Car R. Oxygen diffusion in yttriastabilized zirconia: a new simulation model. J Am Ceram Soc 2004;87:1821-30. 
1 [43] Lee E, Prinz FB, Cai W. Ab initio kinetic Monte Carlo model of ionic conduction in bulk yttria-stabilized zirconia. Model Simul Mater Sci Eng 2012;20:65006.

[44] Bessler WG, Gewies S, Vogler M. A new framework for physically based modeling of solid oxide fuel cells. Electrochim Acta 2007;53:1782-800.

[45] Ren B, Li J, Wen G, Ricardez- Sandoval L, Croiset E. First-Principles Based Microkinetic Modeling of CO2 Reduction at the Ni/SDC Cathode of a Solid Oxide Electrolysis Cell. J Phys Chem C 2018;122:21151-61.

[46] Cai Q, Adjiman CS, Brandon NP. Modelling the 3D microstructure and performance of solid oxide fuel cell electrodes: Computational parameters. Electrochim Acta 2011;56:5804-14. https://doi.org/10.1016/j.electacta.2011.04.065.

[47] Moussaoui H, Debayle J, Gavet Y, Delette G, Hubert M, Cloetens P, et al. 3D geometrical characterization and modelling of solid oxide cells electrodes microstructure by image analysis. Thirteen. Int. Conf. Qual. Control by Artif. Vis. 2017, vol. 10338, 2017, p. 1033804.

[48] Gaiselmann G, Neumann M, Holzer L, Hocker T, Prestat MR, Schmidt V. Stochastic 3D modeling of $\mathrm{La} 0.6 \mathrm{Sr} 0.4 \mathrm{CoO} 3-\$ \delta \$$ cathodes based on structural segmentation of FIB--SEM images. Comput Mater Sci 2013;67:48-62.

[49] Yan Z, Hara S, Shikazono N. Effect of powder morphology on the microstructural characteristics of La0. $6 \mathrm{Sr} 0.4 \mathrm{CoO} .2 \mathrm{Fe} 0.8 \mathrm{O}$ cathode: A Kinetic Monte Carlo investigation. Int J Hydrogen Energy 2017;42:12601-14.

[50] Martin CL, Bouvard D, Shima S. Study of particle rearrangement during powder compaction by the discrete element method. J Mech Phys Solids 2003;51:66793.

[51] Liu X, Martin CL, Delette G, Laurencin J, Bouvard D, Delahaye T. Microstructure 
of porous composite electrodes generated by the discrete element method. $J$ Power Sources 2011;196:2046-54.

[52] Liu X, Martin CL, Bouvard D, Di lorio S, Laurencin J, Delette G. Strength of highly porous ceramic electrodes. J Am Ceram Soc 2011;94:3500-8.

[53] Schneider LCR, Martin CL, Bultel Y, Bouvard D, Siebert E. Discrete modelling of the electrochemical performance of SOFC electrodes. Electrochim Acta 2006;52:314-24.

[54] Sanyal J, Goldin GM, Zhu H, Kee RJ. A particle-based model for predicting the effective conductivities of composite electrodes. J Power Sources 2010;195:6671-9.

[55] Tabei SA, Sheidaei A, Baniassadi M, Pourboghrat F, Garmestani H. Microstructure reconstruction and homogenization of porous Ni-YSZ composites for temperature dependent properties. J Power Sources 2013;235:74-80.

[56] Chiu WKS, Joshi AS, Grew KN. Lattice Boltzmann model for multi-component mass transfer in a solid oxide fuel cell anode with heterogeneous internal reformation and electrochemistry. Eur Phys J Spec Top 2009;171:159-65.

[57] Grew KN, Chiu WKS. A review of modeling and simulation techniques across the length scales for the solid oxide fuel cell. J Power Sources 2012;199:1-13. https://doi.org/10.1016/j.jpowsour.2011.10.010.

[58] Xu H, Dang Z. Lattice Boltzmann modeling of carbon deposition in porous anode of a solid oxide fuel cell with internal reforming. Appl Energy 2016;178:294-307. https://doi.org/https://doi.org/10.1016/j.apenergy.2016.06.007.

[59] Ni M, Leung MKH, Leung DYC. Mathematical modeling of the coupled transport and electrochemical reactions in solid oxide steam electrolyzer for hydrogen 
production. Electrochim Acta 2007;52:6707-18.

[60] Grondin D, Deseure J, Brisse A, Zahid M, Ozil P. Simulation of a high temperature electrolyzer. J Appl Electrochem 2010;40:933-41.

[61] Grondin D, Deseure J, Ozil P, Chabriat J-P, Grondin-Perez B, Brisse A. Computing approach of cathodic process within solid oxide electrolysis cell: Experiments and continuum model validation. J Power Sources 2011;196:9561-7.

https://doi.org/https://doi.org/10.1016/j.jpowsour.2011.07.033.

[62] Menon V, Fu Q, Janardhanan VM, Deutschmann O. A model-based understanding of solid-oxide electrolysis cells (SOECs) for syngas production by $\mathrm{H} 2 \mathrm{O} / \mathrm{CO} 2$ co-electrolysis. J Power Sources 2015;274:768-81. https://doi.org/https://doi.org/10.1016/j.jpowsour.2014.09.158.

[63] Suwanwarangkul R, Croiset E, Fowler MW, Douglas PL, Entchev E, Douglas MA. Performance comparison of Fick's, dusty-gas and Stefan--Maxwell models to predict the concentration overpotential of a SOFC anode. J Power Sources 2003;122:9-18.

[64] Li W, Shi Y, Luo Y, Cai N. Elementary reaction modeling of $\mathrm{CO} / \mathrm{H} 2 \mathrm{O}$ coelectrolysis cell considering effects of cathode thickness. J Power Sources 2013;243:118-30.

[65] $\mathrm{Ni} \mathrm{M}$, Leung $\mathrm{MKH}$, Leung DYC. A modeling study on concentration overpotentials of a reversible solid oxide fuel cell. J Power Sources 2006;163:460-6.

[66] Lay-Grindler E, Laurencin J, Delette G, Aicart J, Petitjean M, Dessemond L. Micro modelling of solid oxide electrolysis cell: From performance to durability. Int $\mathrm{J}$ Hydrogen Energy 2013;38:6917-29. 
https://doi.org/https://doi.org/10.1016/j.ijhydene.2013.03.162.

[67] Tseronis K, Kookos IK, Theodoropoulos C. Modelling mass transport in solid oxide fuel cell anodes: a case for a multidimensional dusty gas-based model. Chem Eng Sci 2008;63:5626-38. https://doi.org/https://doi.org/10.1016/j.ces.2008.07.037.

[68] Cannarozzo M, Del Borghi A, Costamagna P. Simulation of mass transport in SOFC composite electrodes. J Appl Electrochem 2008;38:1011-8.

[69] Shi Y, Luo Y, Cai N, Qian J, Wang S, Li W, et al. Experimental characterization and modeling of the electrochemical reduction of $\mathrm{CO} 2$ in solid oxide electrolysis cells. Electrochim Acta 2013;88:644-53.

[70] Ni M. Modeling of a solid oxide electrolysis cell for carbon dioxide electrolysis. Chem Eng J 2010;164:246-54.

[71] Zhan R, Wang Y, Ni M, Zhang G, Du Q, Jiao K. Three-dimensional simulation of solid oxide fuel cell with metal foam as cathode flow distributor. Int J Hydrogen Energy 2020;45:6897-911.

[72] Li W, Shi Y, Luo Y, Cai N. Elementary reaction modeling of solid oxide electrolysis cells: Main zones for heterogeneous chemical/electrochemical reactions. J Power Sources 2015;273:1-13.

[73] Du Y, Qin Y, Zhang G, Yin Y, Jiao K, Du Q. Modelling of effect of pressure on co-electrolysis of water and carbon dioxide in solid oxide electrolysis cell. Int $\mathrm{J}$ Hydrogen Energy 2019;44:3456-69.

[74] Jin X, Xue X. Computational fluid dynamics analysis of solid oxide electrolysis cells with delaminations. Int J Hydrogen Energy 2010;35:7321-8.

[75] Nerat M, Juričić IDJani. Modelling of anode delamination in solid oxide electrolysis cell and analysis of its effects on electrochemical performance. Int $\mathrm{J}$ 
Hydrogen Energy 2018;43:8179-89.

[76] Navasa M, Graves C, Chatzichristodoulou C, Løye Skafte T, Sundén B, Lund Frandsen H. A three dimensional multiphysics model of a solid oxide electrochemical cell: A tool for understanding degradation. Int J Hydrogen Energy 2018;43:11913-31. https://doi.org/https://doi.org/10.1016/j.jjhydene.2018.04.164.

[77] Ni M, Leung MKH, Leung DYC. Technological development of hydrogen production by solid oxide electrolyzer cell (SOEC). Int $\mathrm{J}$ Hydrogen Energy 2008;33:2337-54. https://doi.org/10.1016/j.ijhydene.2008.02.048.

[78] Luo Y, Shi Y, Li W, Ni M, Cai N. Elementary reaction modeling and experimental characterization of solid oxide fuel-assisted steam electrolysis cells. Int $\mathrm{J}$ Hydrogen Energy 2014;39:10359-73.

[79] Xu H, Chen B, Irvine J, Ni M. Modeling of $\mathrm{CH} 4$-assisted SOEC for H2O/CO2 coelectrolysis. Int J Hydrogen Energy 2016;41:21839-49.

[80] Zhang H, Wang J, Su S, Chen J. Electrochemical performance characteristics and optimum design strategies of a solid oxide electrolysis cell system for carbon dioxide reduction. Int J Hydrogen Energy 2013;38:9609-18.

[81] Xu Z, Ren N, Tang M, Zhang X, Wang F, Li G. Numerical investigations for a solid oxide electrolyte cell stack. Int J Hydrogen Energy 2019;44:20997--21009.

[82] Pozzo M, Lanzini A, Santarelli M. Enhanced biomass-to-liquid (BTL) conversion process through high temperature co-electrolysis in a solid oxide electrolysis cell (SOEC). Fuel 2015;145:39-49.

[83] Zhang G, Xie X, Xie B, Du Q, Jiao K. Large-scale multi-phase simulation of proton exchange membrane fuel cell. Int J Heat Mass Transf 2019;130:555-63.

[84] Hawkes G, O'Brien J, Stoots C, Hawkes B. 3D CFD model of a multi-cell high- 
temperature electrolysis stack. Int J Hydrogen Energy 2009;34:4189-97.

[85] Laurencin J, Kane D, Delette G, Deseure J, Lefebvre-Joud F. Modelling of solid oxide steam electrolyser: Impact of the operating conditions on hydrogen production. J Power Sources 2011;196:2080-93.

[86] Udagawa J, Aguiar P, Brandon NP. Hydrogen production through steam electrolysis: Model-based steady state performance of a cathode-supported intermediate temperature solid oxide electrolysis cell. J Power Sources 2007;166:127-36.

[87] Udagawa J, Aguiar P, Brandon NP. Hydrogen production through steam electrolysis: Control strategies for a cathode-supported intermediate temperature solid oxide electrolysis cell. J Power Sources 2008;180:354-64. https://doi.org/https://doi.org/10.1016/j.jpowsour.2008.01.069.

[88] Udagawa J, Aguiar P, Brandon NP. Hydrogen production through steam electrolysis: Model-based dynamic behaviour of a cathode-supported intermediate temperature solid oxide electrolysis cell. J Power Sources 2008;180:46-55.

[89] Molla TT, Kwok K, Frandsen HL. Modeling the Mechanical Integrity of Generic Solid Oxide Cell Stack Designs Exposed to Long-term Operation. Fuel Cells 2019;19:96-109.

[90] Navasa M, Miao X-Y, Frandsen HL. A fully-homogenized multiphysics model for a reversible solid oxide cell stack. Int J Hydrogen Energy 2019;44:23330-47. https://doi.org/https://doi.org/10.1016/j.ijhydene.2019.06.077.

[91] Salogni A, Colonna P. Modeling of solid oxide fuel cells for dynamic simulations of integrated systems. Appl Therm Eng 2010;30:464-77. https://doi.org/https://doi.org/10.1016/j.applthermaleng.2009.10.007. 
1 [92] Wang C, Chen M, Liu M, Yan J. Dynamic modeling and parameter analysis study on reversible solid oxide cells during mode switching transient processes.

3

4

5 Appl https://doi.org/https://doi.org/10.1016/j.apenergy.2020.114601.

[93] Ollikainen T, Saarinen J, Halinen M, Hottinen T, Noponen M, Fontell E, et al. Dynamic simulation tool APROS in SOFC power plant modeling at Wärtsilä and VTT. ECS Trans 2007;7:1821-9.

[94] Dimian AC, Bildea CS, Kiss AA. Integrated design and simulation of chemical processes. Elsevier; 2014.

[95] Zhang W, Croiset E, Douglas PL, Fowler MW, Entchev E. Simulation of a tubular solid oxide fuel cell stack using AspenPlusTM unit operation models. Energy Convers Manag 2005;46:181-96.

[96] $\mathrm{Ni} \mathrm{M}$, Leung MKH, Leung DYC. Energy and exergy analysis of hydrogen production by solid oxide steam electrolyzer plant. Int $\mathrm{J}$ Hydrogen Energy 2007;32:4648-60.

[97] Mingyi L, Bo Y, Jingming X, Jing C. Thermodynamic analysis of the efficiency of high-temperature steam electrolysis system for hydrogen production. J Power Sources 2008;177:493-9. https://doi.org/https://doi.org/10.1016/j.jpowsour.2007.11.019.

[98] Stempien JP, Ding OL, Sun Q, Chan SH. Energy and exergy analysis of Solid Oxide Electrolyser Cell (SOEC) working as a $\mathrm{CO} 2$ mitigation device. Int $\mathrm{J}$ Hydrogen Energy 2012;37:14518-27. https://doi.org/https://doi.org/10.1016/j.ijhydene.2012.07.065.

[99] Samavati M, Santarelli M, Martin A, Nemanova V. Thermodynamic and economy analysis of solid oxide electrolyser system for syngas production. 
https://doi.org/https://doi.org/10.1016/j.energy.2017.01.067.

[100] Rivera-Tinoco R, Farran M, Bouallou C, Auprêtre F, Valentin S, Millet P, et al. Investigation of power-to-methanol processes coupling electrolytic hydrogen production and catalytic CO2 reduction. Int J Hydrogen Energy 2016;41:454659.

[101] Buttler A, Koltun R, Wolf R, Spliethoff H. A detailed techno-economic analysis of heat integration in high temperature electrolysis for efficient hydrogen production. Int J Hydrogen Energy 2015;40:38-50.

[102] Wang L, Chen M, Küngas R, Lin T-E, Diethelm S, Maréchal F, et al. Power-tofuels via solid-oxide electrolyzer: Operating window and techno-economics. Renew Sustain Energy Rev 2019;110:174-87. https://doi.org/https://doi.org/10.1016/j.rser.2019.04.071.

[103] Ebbesen S, Jensen S, Hauch A, Mogensen M. High Temperature Electrolysis in Alkaline Cells, Solid Proton Conducting Cells, and Solid Oxide Cells. Chem Rev 2014;114. https://doi.org/10.1021/cr5000865.

[104] Wang L, Pérez-Fortes M, Madi H, Diethelm S, herle J Van, Maréchal F. Optimal design of solid-oxide electrolyzer based power-to-methane systems: A comprehensive comparison between steam electrolysis and co-electrolysis. Appl Energy 2018;211:1060-79. https://doi.org/https://doi.org/10.1016/j.apenergy.2017.11.050.

[105] Wang L, Rao M, Diethelm S, Lin T-E, Zhang H, Hagen A, et al. Power-tomethane via co-electrolysis of $\mathrm{H} 2 \mathrm{O}$ and $\mathrm{CO} 2$ : The effects of pressurized operation and internal methanation. Appl Energy 2019;250:1432-45. https://doi.org/https://doi.org/10.1016/j.apenergy.2019.05.098. 
1 [106] Mohammadi M, Noorollahi Y, Mohammadi-ivatloo B, Yousefi H. Energy hub: From a model to a concept - A review. Renew Sustain Energy Rev 2017;80:1512-27. https://doi.org/https://doi.org/10.1016/j.rser.2017.07.030.

4

[107] Mohammadi M, Noorollahi Y, Mohammadi-ivatloo B, Hosseinzadeh M, Yousefi $\mathrm{H}$, Khorasani ST. Optimal management of energy hubs and smart energy hubs - A review. Renew Sustain Energy Rev 2018;89:33-50. https://doi.org/https://doi.org/10.1016/j.rser.2018.02.035.

[108] Parisio A, Del Vecchio C, Vaccaro A. A robust optimization approach to energy hub management. Int J Electr Power Energy Syst 2012;42:98-104. https://doi.org/https://doi.org/10.1016/j.ijepes.2012.03.015.

[109] Hutty TD, Dong S, Brown S. Suitability of energy storage with reversible solid oxide cells for microgrid applications. Energy Convers Manag 2020;226:113499. https://doi.org/https://doi.org/10.1016/j.enconman.2020.113499.

[110] Colombo P, Saeedmanesh A, Santarelli M, Brouwer J. Dynamic dispatch of solid oxide electrolysis system for high renewable energy penetration in a microgrid. Energy Convers Manag 2020;204:112322. https://doi.org/https://doi.org/10.1016/j.enconman.2019.112322.

[111] Rispoli N, Vitale F, Califano F, Califano M, Polverino P, Rosen MA, et al. Constrained optimal design of a reversible solid oxide cell-based multiple load renewable microgrid. J Energy Storage 2020;31:101570. https://doi.org/https://doi.org/10.1016/j.est.2020.101570.

[112] Andersson M, Yuan J, Sundén B. Review on modeling development for multiscale chemical reactions coupled transport phenomena in solid oxide fuel cells. Appl Energy 2010;87:1461-76.

[113] Business AS. PSE: Products - gPROMS - Hybrid Multizonal CFD | Process 
Systems Enterprise n.d. https://www.psenterprise.com/products/gproms/hybridmultizonal.

3 [114] Hajimolana SA, Tonekabonimoghadam SM, Hussain MA, Chakrabarti MH, Jayakumar NS, Hashim MA. Thermal stress management of a solid oxide fuel cell using neural network predictive control. Energy 2013;62:320-9.

6 [115] Hajimolana SA, Soroush M. Dynamics and control of a tubular solid-oxide fuel 7 cell. Ind Eng Chem Res 2009;48:6112-25.

8 [116] Yang Z, Jiao K, Liu Z, Yin Y, Du Q. Investigation of performance heterogeneity of PEMFC stack based on 1+1D and flow distribution models. Energy Convers Manag 2020;207:112502.

11 [117] Xie B, Jiang Y, Zhang G, Yin Y, Du Q, Jiao K. Large-Scale Simulation of PEM 12 Fuel Cell Using a “3D+ 1D” Model. 2020. 